\title{
Molecular Systems Combining Porphyrinoids and N-Heterocyclic Carbenes
}

\author{
Jean-François Longevial, ${ }^{[a]}$ Clémence Rose, ${ }^{[a]}$ Ludivine Poyac, ${ }^{[a]}$ Sébastien Clément ${ }^{[a]}$ and Sébastien \\ Richeter ${ }^{*[a]}$ \\ Dedication to Dr. Romain Ruppert on the occasion of his $65^{\text {th }}$ birthday \\ [a] Dr. J.-F. Longevial, Dr. C. Rose, L. Poyac, Pr. S. Clément, Dr. S. Richeter \\ ICGM, Univ. Montpellier, CNRS, ENSCM, Montpellier, France \\ E-mail: sebastien.richeter@umontpellier.fr \\ https://orcid.org/0000-0001-5284-0931; https://www.icgm.fr/sebastien-richeter
}

\begin{abstract}
Porphyrins and N-heterocyclic carbenes (NHCs) are both relevant ligands in the fields of coordination and organometallic chemistry. Despite evident structural differences, porphyrins and $\mathrm{NHCs}$ have a lot in common such as their ability to form strong metalligand bonds and their use in catalysis, materials science and biomedicine. During the last decade, several molecular systems combining porphyrins and $\mathrm{NHC}$ ligands were reported in the literature. The present review gathers relevant examples where NHC ligands are either axially bonded to metalloporphyrins or covalently attached to the porphyrin cores. Structural diversity, electronic interplay between porphyrins and NHCs and some relevant applications in catalysis and biomedicine are notably described. Finally, molecular systems combining $\mathrm{NHC}$ with other original porphyrinoids such as $\mathrm{N}$ confused porphyrins, subporphyrins and norcorroles are also presented.
\end{abstract}

\section{Introduction}

Combining porphyrinoids and $\mathrm{N}$-heterocyclic carbenes (NHCs) may seem counterintuitive at first glance when considering their structure. However, when looking further ahead, porphyrins and $\mathrm{NHCs}$ have a lot in common. Both are extremely investigated ligands which can strongly bind about $50 \%$ of the elements of the periodic table (see Figures 1 and 2). Their organic structure can also be quite easily modified allowing to tune their steric and electronic properties. Merging porphyrinoids and NHCs within unimolecular systems may lead to multimetallic species with mixed properties and potentially new applications. The present review is focused on molecular systems combining porphyrinoids and $\mathrm{NHC}$ ligands reported in the literature during the last decade. It is notably described how such systems could be synthesized through the formation of axial coordination bonds between NHCs and the inner metal cations of metalloporphyrins, or through covalent bonds between NHCs and meso- or $\beta$ carbons of the porphyrin core. Structural diversity and some applications in catalysis, biomedicine or energy transfer studies are also discussed along the review. Finally, molecular systems combining $\mathrm{NHCs}$ with other original porphyrinoids such as $\mathrm{N}$ confused porphyrins, subporphyrins and norcorroles are also presented. The two following paragraphs give some general information about porphyrins and NHCs that can be easily skipped by accustomed readers.

\subsection{Porphyrins}

Porphyrins are macrocyclic aromatic compounds containing four pyrrolic units (Figure 1A). These compounds feature an inner cavity which can bind $\sim 47 \%$ of the elements of the periodic table (Figure 1B). They are ubiquitous in nature, whether for $\mathrm{O}_{2}$ and $\mathrm{CO}_{2}$ transport in blood (hematoporphyrins) or in enzymatic systems (P450 cytochrom system). Other porphyrinoids such as chlorophyll derivatives play key roles in photosynthetic systems to collect and convert light energy into chemical energy. The nomenclature used for naming the different positions of the porphyrin core is described in Figure 1A. The $\alpha$ - and $\beta$-positions take root from the pyrrole nomenclature, and the four carbon atoms between two neighbouring pyrrole rings are named meso positions. ${ }^{[1]}$ These meso positions often bear alkyl or aromatic moieties native from their synthesis and usually serve as solubilizing groups in organic solvents, as scaffold for further functionalization or as probe for characterization by NMR spectroscopy. ${ }^{[2]}$ Moreover, the electron withdrawing or donating character of the meso groups can impact the electronic properties and the reactivity of the porphyrin macrocycle. ${ }^{[3]}$
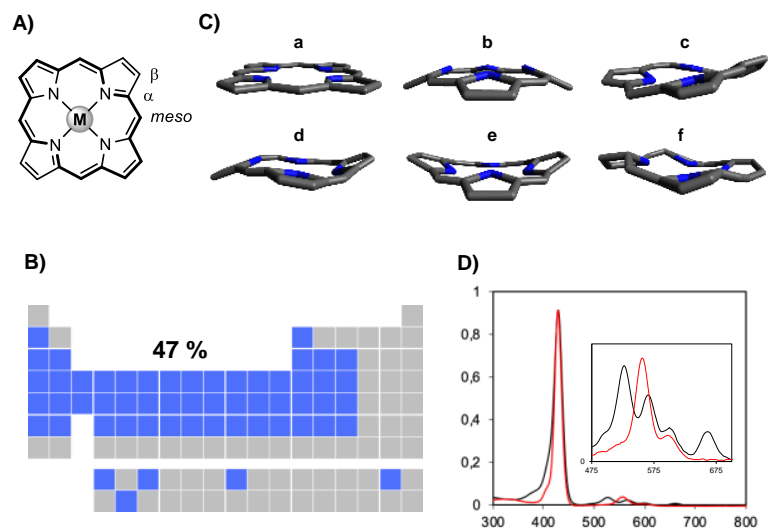

D)

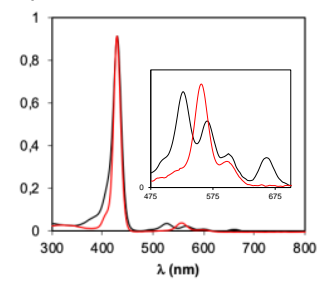

Figure 1. A) Structure of porphyrins and their nomenclature. Thick bonds represent their aromatic path. B) Representation of the periodic table of elements: blue cases are elements for which porphyrin complexes are known. C) Some example of conformations adopted by porphyrins a) flat; b) rounded or dome; c) crinkled; d) wave; e) saddle shape; f) twisted. D) Examples of UV-Vis absorption spectra of a free-base porphyrin (black line) and a metalated porphyrin (red line). References for the UV-visible absorption spectra are $\mathrm{H}_{2}$ TPP and Ni"TPP, respectively, with TPP $=5,10,15,20$ - meso-tetraphenylporphyrin. 
Porphyrins are also quite flexible macrocycles which can adopt different conformations according to their peripheral substituents and their inner metal cations. Some representative conformations are displayed in Figure $1 \mathrm{C} .{ }^{[4]}$ From an electronic point of view, porphyrins are $\pi$-extended macrocycles containing $22 \pi$ electrons of which 18 are involved in the aromaticity (thick bonds in Figure 1A). As a consequence, porphyrins strongly absorb light in the visible and the near-UV regions (Figure 1D). UV-visible absorption spectra of porphyrins usually display an intense absorption band (Soret band) at $390-450 \mathrm{~nm}$ and several weak absorption bands ( $Q$ bands) between 500 and $700 \mathrm{~nm}$. The number of $Q$ bands depends on the global symmetry of the porphyrin when metallated (two bands) or not (four bands).

\subsection{N-Heterocyclic Carbenes}

Carbenes are neutral organic species containing a divalent and $s p^{2}$ hybridized carbon atom possessing six valence electrons. ${ }^{[5]}$ Among them, $\mathrm{N}$-heterocyclic carbenes (NHCs) which were first discovered by Wanzlick have emerged as versatile ligands in the field of organometallic chemistry. ${ }^{[6]}$ Historically, the isolation of the first persistent free NHCs was done by Arduengo in $1991 .{ }^{[7]} \mathrm{NHCs}$ are carbenes possessing at least one nitrogen atom at the vicinity of the divalent carbon atom. Most investigated $\mathrm{NHCs}$ are based on imidazole skeletons (imidazolylidenes, imidazolinylidenes, benzimidazolylidenes), but other heteroatoms such as oxygen (oxazolylidene) or sulphur (thiazolylidene) can also be present at the vicinity of the carbene. Therefore, a wide variety of different structures can be envisaged for NHCs (Figure 2A). ${ }^{[8]}$ Another well-known class of NHCs are the so called abnormal NHCs where canonical valence bond representation requires the addition of charges on some nuclei. ${ }^{[9]}$

A)

$$
\text { imidazolinylidene }
$$

B)

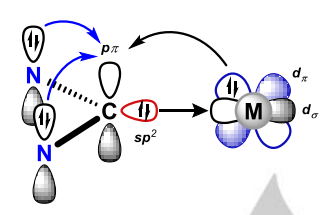

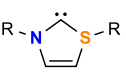
thiazolylidene

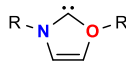
oxazolylidene



\section{rop}

\section{WILEY-VCH}

populating the $p_{\pi}$ orbital (Figure 2B). Consequently, NHCs are mostly strong $\sigma$-donor ligands with a weak $\pi$-accepting character, and their bond strength when coordinated to a metal can be up to twice as the phosphine ones. ${ }^{[11]}$ Moreover, steric and electronic properties of the carbene could be tuned through the symmetric or asymmetric functionalization of the neighbouring heteroatoms. ${ }^{[12]}$ Combining all these features, NHCs which are able to bind $\sim 52 \%$ of the elements of the periodic table are among the most investigated ligands during the last two decades (Figure 2C). Indeed, NHCs are useful ligands in the field of catalysis, ${ }^{[13]}$ to design new metallodrugs ${ }^{[14]}$ or self-assembled molecular structures for host-guest chemistryy and supramolecular chemistry. ${ }^{[16]}$

\section{NHC Axially Bonded to Metalloporphyrins}

\subsection{The Trans Effect of Axial Carbene Ligands}

Porphyrins containing metal ions such as iron, ruthenium, osmium, cobalt, rhodium or iridium can be used as catalysts for carbene or nitrene transfer reactions to $\mathrm{C}=\mathrm{C}$ bonds (cyclopropanation, aziridination), insertion reactions into $\mathrm{X}-\mathrm{H}$ bonds $(X=C, N$ or $O)$, or ylide forming reactions. ${ }^{[17]}$ Key intermediates in these reactions are metal-carbene ( $\left.M=C R R^{\prime}\right)$ or metal-nitrene $(M=N R)$ species, while porphyrins are blocking the four equatorial coordination sites. Reactivity of these metalcarbene (or nitrene) complexes strongly depends on the nature of the remaining trans axial ligand on the opposite sixth coordination site. Representative examples are the two osmium(II) complexes $\left[\mathrm{Os}\left(\mathrm{F}_{20}-\mathrm{TPP}\right)\left(\mathrm{CPh}_{2}\right)_{n}\right]$ with $\mathrm{n}=1$ or $2\left(\mathrm{~F}_{20}-\mathrm{TPP}=5,10,15,20\right.$ - mesotetrakis(pentafluorophenyl)porphyrin). The biscarbene complex $(n=2)$ is able to catalyse alkene cyclopropanation and $\mathrm{C}-\mathrm{H}$ functionalization reactions, whereas the corresponding monocarbene complex $(n=1)$ is inert. This clearly demonstrates that the reactivity of the $\mathrm{Os}=\mathrm{CPh}_{2}$ moiety is strongly improved by the trans influence of the opposite $\mathrm{Ph}_{2} \mathrm{C}$ ligand. ${ }^{[18]} \mathrm{NHCs}$ are particularly investigated as ancillary ligands in the field of catalysis because they can form kinetically inert NHC-metal bonds with a large panel of metal ions in low and high oxidation states. Because of their strong trans effect reminiscent of that of $\mathrm{Ph}_{2} \mathrm{C}$, $\mathrm{NHCs}$ were investigated as axial ligands of metalloporphyrins with the primary objective to evaluate the structural and/or catalytic properties of the obtained complexes.

\subsection{Cobalt(II/III) and Manganese(II) Complexes}

Albrecht and co-workers were the first to report axial coordination of NHCs to metalloporphyrins. ${ }^{[19]} \mathrm{NHC}$ cobalt complexes were relatively scarce at that time, because most of them are air and moisture sensitive and must be carefully handled under inert atmosphere to avoid unwanted redox processes. For this reason, Albrecht's group used a porphyrin macrocycle as tetradendate ligand to stabilize the diamagnetic cobalt(III) cation and investigated axial ligation of imidazol-2-ylidenes on the resulting cobalt(III) porphyrin complexes. Steric properties of imidazol-2-ylidenes are governed by the wingtip substituents on the nitrogen atoms pointing towards the metal centre. Therefore, NHCs containing small and flexible alkyl substituents such as methyl and ethyl groups were used to minimize steric repulsion. In a first approach, 1,3-dimethylimidazolium carboxylate was 
used as NHC precursor and reacted slowly with [Co(TPP)Cl] to obtain the corresponding low-spin mono(NHC) cobalt(III) complex 1 in $79 \%$ yield (Scheme 1). Interestingly, coordination of a second $\mathrm{NHC}$ ligand on the opposite sixth coordination site of cobalt(III) (replacement of the chloride ligand) was unfavourable even if $\mathrm{NHC}$ ligand was used in excess. Nevertheless, the chloride ligand could be abstracted by $\mathrm{AgBF}_{4}$ (complex 2) and the sixth coordination site could be occupied by Lewis bases such as methanol, for example (complex 3). This six-coordinate complex 3 was characterized by $\mathrm{X}$-ray diffraction analysis. The $\mathrm{C}_{\mathrm{NHC}}-\mathrm{Co}^{\prime \prime \prime}$ bond distance of $1.93 \AA$ is within expectation reflecting the covalent character of this bond. Interestingly, cobalt(III) is slightly pulled out of the macrocycle by the NHC and the steric demand of the $\mathrm{N}$-methyl groups induced a ruffling of the porphyrin core. This can explain why a second NHC ligand could not bind the cobalt(III) centre on the opposite axial coordination site.
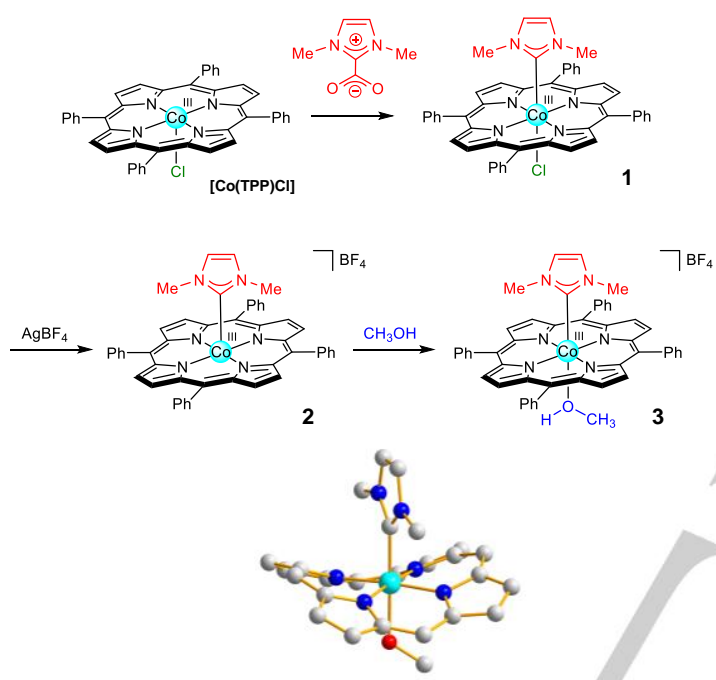

Scheme 1. Top: synthesis of mono(NHC) cobalt(III) porphyrin complexes 1-3. Bottom: X-ray crystal structure of complex 3 . Hydrogen atoms and meso phenyl groups are omitted for clarity.

Almost a decade later, the corresponding paramagnetic cobalt(II) porphyrin $\mathbf{4}$ bearing axial NHC ligand was reported. ${ }^{[20]}$ In this case, a low-spin five-coordinate complex was obtained ( $\mathrm{S}=$ 1/2). The $\mathrm{C}_{\mathrm{NHC}}-\mathrm{Co}^{\prime \prime}$ bond distance of $2.16 \AA$ is much longer compared to the previous complex $3(+0.23 \AA)$ and, as a consequence, the macrocycle distortion is lower in this case (Figure 3, left). The structure of this complex can be compared to the one of the corresponding cobalt(II) complex 5 with 2methylimidazole (2-Melmi) as axial ligand (Figure 3, middle). The $\mathrm{C}_{\mathrm{NHC}}-\mathrm{CO}$ " bond is slightly shorter compared to the $\mathrm{N}_{2-\text { Melmi- }}-\mathrm{Co}^{\prime \prime}$ distance of $2.18 \AA$ suggesting a stronger (or comparable) ligand field of NHC compared to imidazole. Compared to cobalt(II) complexes, the corresponding manganese(II) complex 6 shows a larger out-of-plane displacement indicating a high-spin state $(\mathrm{S}=$ $5 / 2$ ). The manganese atom is too far out-of-plane to permit effective interaction with a sixth ligand. The $\mathrm{C}_{\mathrm{NHC}}-\mathrm{Mn}^{\prime \prime}$ bond distance of $2.24 \AA$ is also longer compared to the $\mathrm{C}_{\mathrm{NHC}}-\mathrm{Co}^{\text {ll }}$ bond distance (Figure 3 , right) and the porphyrin core consequently adopts a dome geometry.
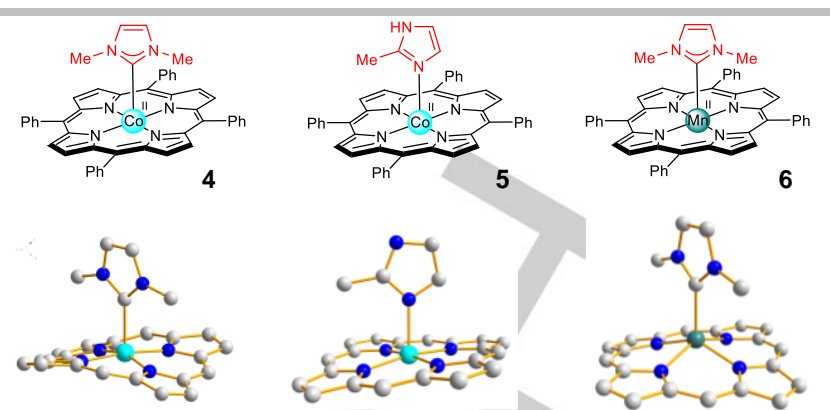

Figure 3. Top: structures of cobalt(II) complexes $\mathbf{4}$ and $\mathbf{5}$ and manganese(II) complex 6. Bottom: X-ray crystal structures of complexes 4 (left), 5 (middle) and 6 (right). Hydrogen atoms and meso phenyl groups are omitted for clarity.

\subsection{Rhodium(III) Complexes}

Synthesis of mono- and bis(NHC) rhodium(III) porphyrin complexes were reported by Albrecht and co-workers. ${ }^{[21]}$ They used a similar synthetic strategy to the one used for the synthesis of cobalt(III) porphyrin complexes (Scheme 2). Mono(NHC) rhodium(III) complex 7 was obtained by thermal decarboxylation of 1,3-dimethylimidazolium carboxylate in the presence of [Rh(TPP)Cl] for 3 hours. Interestingly, the bis(NHC) rhodium(III) complex $\mathbf{8}$ was isolated as a by-product during the formation of complex 7 , but its yield could be increased by extending reaction time up to 18 hours. These two mono- and bis(NHC) rhodium(III) complexes $\mathbf{7}$ and $\mathbf{8}$ were both characterized by X-ray diffraction analyses. The porphyrin core of the mono(NHC) rhodium(III) complex $\mathbf{7}$ adopts a ruffled conformation due to the steric interaction with the two $\mathrm{N}$-methyl groups pointing towards the macrocycle. The rhodium centre is also slightly pulled out of the porphyrin core by the $\mathrm{NHC}$. The $\mathrm{C}_{\mathrm{NHC}}-\mathrm{Rh}^{\text {III }}$ bond distance of 2.05 $\AA$ is identical to the $\mathrm{N}_{\mathrm{N}-\mathrm{Melmi}}-\mathrm{Rh}^{\text {III }}$ distance in the corresponding complex 9 where the $\mathrm{NHC}$ is replaced by $\mathrm{N}$-methylimidazole (NMelmi, Figure 4). Because N-Melmi does not have methyl groups pointing towards the porphyrin core, the macrocycle adopts a rather planar conformation. The $\mathrm{Rh}^{\text {III-}}-\mathrm{Cl}$ bond distance is $0.1 \AA$ longer when $\mathrm{NHC}$ is trans to $\mathrm{Cl}(2.43 \AA$ vs. $2.33 \AA$ with N-Melmi) reflecting the $\mathrm{C}_{\mathrm{NHC}}-\mathrm{Rh}^{\text {III }}$ bond strength. The porphyrin core of the bis $(\mathrm{NHC})$ rhodium(III) complex $\mathbf{8}$ is more ruffled compared to the one of the mono(NHC) rhodium(III) complex 7. The two $\mathrm{C}_{\mathrm{NHC}}-\mathrm{Rh}^{\text {III }}$ bond distances of 2.14 and $2.12 \AA$ are significantly longer than the one measured in the mono(NHC) rhodium(III) 7 complex (2.05 $\AA)$ indicating the strong trans influence of the NHC. As it can be seen in Scheme 2, there is a $90^{\circ}$ torsion angle between the two $\mathrm{NHC}$ planes and, as a consequence, the four $\mathrm{N}-\mathrm{Me}$ groups point two at a time towards the meso carbons of the ruffled porphyrin core to minimize steric repulsions.

These complexes were used to catalyse the aerobic oxidation of benzyl alcohol into benzaldehyde. The results obtained show substantial differences in their reactivity after 24 hours of reaction increasing in the order mono(N-Melmi)Rh 9 $(19 \%$ yield $)<$ [Rh(TPP)Cl] $(45 \%$ yield $)<$ mono $(\mathrm{NHC}) \mathrm{Rh} 7$ (72\% yield $)<$ bis(NHC)Rh 8 (92\% yield). The high catalytic activity observed for the bis(NHC) rhodium(III) complex 8 implies that at least one NHC is substituted by the benzyl alcohol substrate in the course of the reaction. NHC dissociation is favoured by the trans influence of the opposite NHC (electronic effect) and also by the distorted porphyrin core which becomes flatter and more 
aromatic after the release of one NHC (steric effect). Interestingly, light irradiation significantly improved the initial catalytic activity of the bis(NHC) rhodium(III) complex 8 and $40 \%$ conversion was accomplished in 0.5 hour vs. $1 \mathrm{~h}$ for the same reaction in the dark.



Scheme 2. Top: synthesis of mono- and bis(NHC) rhodium(III) complexes 7 and 8. Bottom: X-ray crystal structures of complexes $\mathbf{7}$ (left) and $\mathbf{8}$ (right). Hydrogen atoms and meso phenyl groups are omitted for clarity.
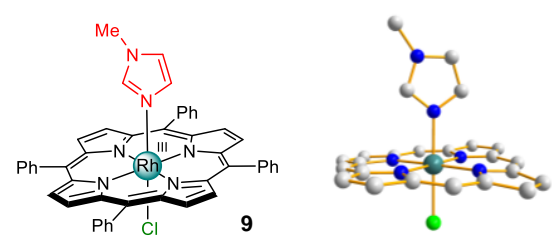

Figure 4. Left: structure of mono(imidazole) rhodium(III) complex 9 . Right: Xray crystal structure of complex $\mathbf{9}$. Hydrogen atoms and meso phenyl groups are omitted for clarity.

Considering that $\mathrm{NHC}$ can form very stable bonds with metal ions requires caution when considering axial coordination on metalloporphyrins. Woo and co-workers reported the synthesis of mono(NHC) rhodium(III) porphyrin complexes, which were obtained by generating $\mathrm{NHC}$ through the deprotonation of imidazolium salts (Figure 5). ${ }^{[22]}$ As for Albrecht's complexes, the structural analysis of the mono(NHC) rhodium(III) porphyrin complex 10 with $\mathrm{NHC}=1$-butyl-3-methylimidazol-2-ylidene revealed that the porphyrin core is ruffled (Figure 5, right). The $\mathrm{C}_{\mathrm{NHC}}-\mathrm{Rh}^{\text {III }}$ bond distance of $2.25 \AA$ is much longer compared to the distances measured for the previous rhodium(III) complexes (7 and 8 with 2.05 and 2.12-2.14 A respectively). ${ }^{[21]}$ This may be due to the presence of the methyl group on the opposite axial coordination site. Thus, the $\mathrm{C}_{\mathrm{NHC}}-\mathrm{Rh}^{\mathrm{III}}$ bond has a nearly pure $\sigma$ bonding character. In addition to the classical mesoaryl-porphyrin $\mathrm{C}-\mathrm{C}$ bonds rotation, variable temperature experiments also revealed additional dynamic processes which consist in NHC exchange reactions. This experiment also supports the hypothesis formulated by Albrecht and co-workers on the release of one $\mathrm{NHC}$ ligand of bis $(\mathrm{NHC})$ rhodium(III) complexes $\mathbf{8}$ in the course of the catalytic process.
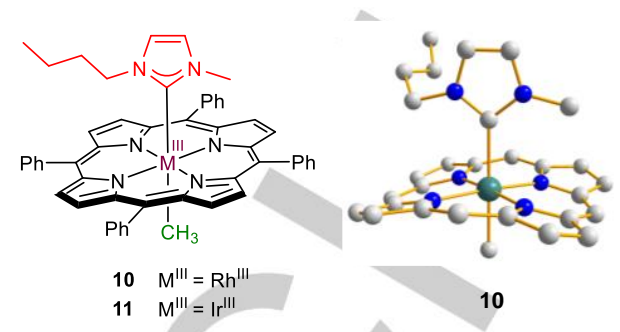

Figure 5. Left: structures of mono(NHC) rhodium(III) 10 and iridium(III) 11 complexes. Right: X-ray crystal structure of complex 10. Hydrogen atoms and meso phenyl are groups omitted for clarity.

\subsection{Iridium(III) Complexes}

In parallel to their studies on rhodium(III) complexes, Woo and co-workers also reported the synthesis of mono(NHC) iridium(III) porphyrin complexes, which were also obtained by $\mathrm{NHC}$ generation through the deprotonation of imidazolium salts. ${ }^{[22]}$ The authors found that NHCs were more strongly bound to iridium(III) than to rhodium(III). Indeed, binding constants of NHCs with iridium(III) porphyrins are around one order of magnitude larger $(\log K=5.5 \pm 0.2$ vs. $4.6 \pm 0.2$ for $\mathrm{NHC}=1,3-$ dimethylimidazol-2-ylidene). The structure of the mono(NHC) iridium(III) porphyrin complex 11 with $\mathrm{NHC}=1$-butyl-3methylimidazol-2-ylidene is very similar to the one of the corresponding rhodium(III) complex (Figure 5). The $\mathrm{C}_{\mathrm{NHC}}-\mathrm{Ir}{ }^{\prime \prime \prime}$ bond distance of $2.19 \AA$ is shorter than that of the rhodium complex 10 $(2.25 \AA)$ and in agreement with the fact that $\mathrm{C}_{\mathrm{NHC}}-\mathrm{Ir}^{\mathrm{III}}$ bond is stronger. The $\mathrm{C}_{\mathrm{Me}}-\mathrm{Ir}^{\mathrm{III}}$ bond distance $(2.10 \AA)$ of the trans methyl ligand is longer compared to the corresponding $\mathrm{C}_{\mathrm{Me}}-\mathrm{Rh}^{\text {"II }}$ bond distance $(2.07 \AA)$. Both distances are longer than those of the pentacoordinate complexes $\left[\mathrm{Rh}(\mathrm{TPP}) \mathrm{CH}_{3}\right] \quad\left(\begin{array}{ll}1.97 & \AA\end{array}\right)$ and $\left[\operatorname{lr}(\mathrm{TPP}) \mathrm{CH}_{3}\right](2.06 \AA)$ because of the trans influence of the NHC. Substantial deformation of the porphyrin macrocycle of mono(NHC) iridium(III) complex $\mathbf{1 1}$ was also observed as it was the case for the corresponding rhodium(III) complex $\mathbf{1 0}$.

Che, Lok and co-workers recently reported the synthesis of a panel of mono- and bis $(\mathrm{NHC})$ iridium(III) porphyrin complexes. ${ }^{[23]}$ These compounds were prepared by reacting bis $(\mathrm{NHC})$ silver(I) complex with [Ir"I(porphyrin)(CO)Cl] via transmetalation reactions as illustrated in Scheme 3. Mono- and bis(NHC) iridium(III) complexes were obtained in $60-74 \%$ and 70 $96 \%$ yields, respectively. Corresponding complexes with octaethylporphyrins (OEP) were also prepared. X-ray diffraction structures of several bis(NHC) iridium(III) complexes were obtained and the one of complex $\mathbf{1 2}$ is represented in Scheme 3. In all X-ray crystal structures, torsion angles between the two $\mathrm{NHC}$ planes are $\sim 90^{\circ}$. This structural feature is related to the ruffling deformation of porphyrin ligands as described above for complex 8. The $\mathrm{C}_{\mathrm{NHC}}-\mathrm{Ir}^{\text {III }}$ distances in the range of 2.10-2.15 $\AA$ are longer than those of Ir-NHC complexes reported in the literature without porphyrin ligand. This effect can once again be attributed to the trans influence of the opposite NHC ligand and the steric interactions of the wingtip $\mathrm{N}$-groups with the meso carbon atoms of the porphyrin core. Interestingly, the $\mathrm{C}_{\mathrm{NHC}}-\mathrm{Ir}^{\mathrm{III}}$ distance is 
reduced by $0.05 \AA$ when meso $p$-tolyl groups are replaced by pentafluorophenyl groups.

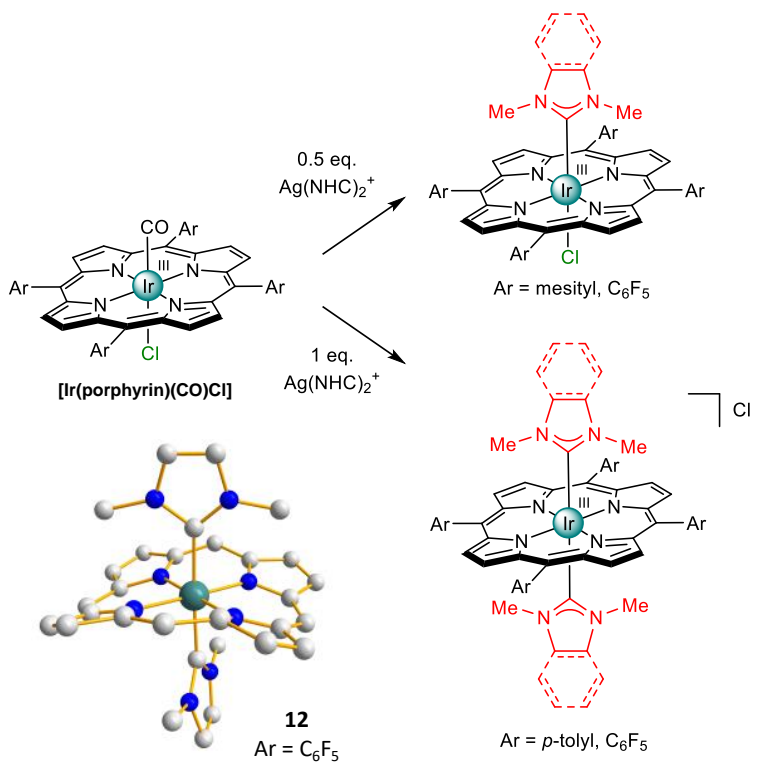

Scheme 3. Synthesis of mono- and bis(NHC) iridium(III) complexes. Bottom: Xray crystal structure of complex 12 . Hydrogen atoms and meso aryl groups are omitted for clarity.

The UV-visible absorption spectra of mono- and bis $(\mathrm{NHC})$ iridium(III) porphyrin complexes display split Soret absorption bands. Bis(NHC) iridium(III) porphyrin complexes (including those with OEP) are effective photosensitizers for singlet oxygen $\left({ }^{1} \mathrm{O}_{2}\right)$ generation. ${ }^{1} \mathrm{O}_{2}$ quantum yields of $\Phi_{\Delta}=0.64$ and 0.88 were measured for complexes with TTP $(5,10,15,20$-meso-tetrakis $(p$ tolyl)porphyrin) and OEP, respectively, and 1,3-dimethylimidazol2-ylidene as axial NHCs. The authors used for the first time these complexes as photosensitizers to treat cancer cells. These complexes appeared to be more cytotoxic in the dark than cisplatin used as reference compound with $\mathrm{IC}_{50}$ values at submicromolar levels. Anticancer effect could be enhanced by photodynamic effect upon light irradiation with very low $\mathrm{IC}_{50}$ values in the nanomolar range. Bioimaging studies tend to show that endoplasmic reticulum is the main target of these iridium(III) complexes. One complex has also significant inhibitory effects against tumour growth in a nude mouse model. Therefore, this interesting study demonstrates that such complexes are promising candidates to develop new therapeutics having strong anticancer properties in the dark and that can be activated upon light irradiation for photodynamic therapy (PDT).

\subsection{Ruthenium(II) Complexes}

Che, Lo and co-workers reported the synthesis of several ruthenium(II) porphyrin complexes with two axial NHCs. ${ }^{[24]}$ These bis $(\mathrm{NHC})$ ruthenium(II) complexes were obtained by reacting $[R u(T P P)(C O)]$ with an excess of the corresponding (benz)imidazolium salts in the presence of a base like KOtBu (Scheme 4). One of these compounds, namely complex 13, was characterized by X-ray diffraction analysis. Interestingly, the planes of the two axial NHCs are not mutually orthogonal, as it is the case for rhodium(III) and iridium(III) complexes (vide supra), but are coplanar. As a consequence, the porphyrin core is not ruffled, but completely flat because of the similar steric pressure induced by the four methyl groups on two opposite sides of the macrocycle. The two $\mathrm{C}_{\mathrm{NHC}}-\mathrm{Ru}^{\prime \prime}$ bond distances of $2.07 \AA$ are equivalent and in agreement with those reported for complexes incorporating Ru-C simple bonds. ${ }^{[25]}$ These complexes incorporating two axial NHCs are catalytically active towards the cyclopropanation of styrene with ethyl diazoacetate, the aziridination of alkenes with pentafluorophenyl azide and the insertion of carbenes and nitrenes into $\mathrm{C}-\mathrm{H}$ bonds. ${ }^{[24]}$ Insertion of carbenes into $\mathrm{N}-\mathrm{H}$ bonds of peptide terminal amino groups was also described. Reported yields and selectivities are excellent. ${ }^{[24]}$ Interestingly, a ruthenium(II) porphyrin complex with two axial $\mathrm{NHC}$ ligands (benzimidazol-2-ylidenes) and equipped with chiral meso functionalities is able to catalyse carbene/nitrene transfer and insertion with high enantioselectivities up to $98 \%$ ee. ${ }^{[24]}$
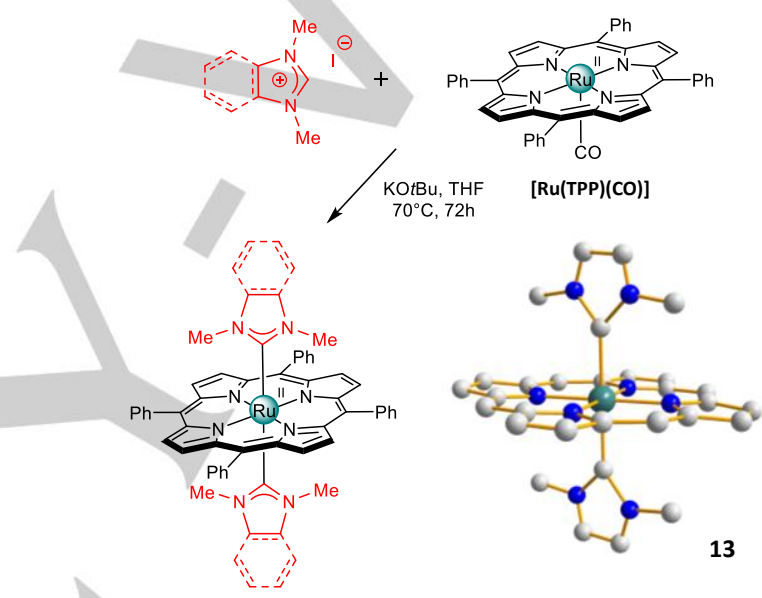

Scheme 4. Synthesis of bis(NHC) ruthenium(II) porphyrin complexes. Right: Xray crystal structure of complex 13. Hydrogen atoms and meso phenyl groups are omitted for clarity.

As for rhodium(III) complexes, the proposed mechanism for carbene transfer insertion reactions implies the release of one $\mathrm{NHC}$ ligand and considers the catalytically active species as the five-coordinate mono(NHC) ruthenium(II) complex with one vacant axial coordination site. To confirm this hypothesis, the mono(NHC) ruthenium(II) complex 14 with a THF molecule coordinated trans to the $\mathrm{NHC}$ was prepared and characterized by $\mathrm{X}$-ray diffraction analysis (Figure 6). ${ }^{[24]}$ The measured $\mathrm{C}_{\mathrm{NHC}}-\mathrm{Ru}^{\mathrm{II}}$ bond distance $(2.00 \AA)$ is slightly shorter than that of complex 13 $(2.07 \AA)$ reflecting the weaker trans influence of the THF molecule compared to the NHC. The porphyrin also appeared to be less planar because of the steric pressure induced by the two methy groups of the NHC only present on one side of the porphyrin. The observed catalytic activities for the mono(NHC) ruthenium(II) complex 14 are similar to that of the bis(NHC) ruthenium(II) complex 13 in the cyclopropanation of styrene with ethyl diazoacetate. This observation strongly supports the hypothesis that one $\mathrm{NHC}$ is released from the metal center and that the remaining $\mathrm{NHC}$ coordinated to ruthenium improves carbene transfer reaction. Moreover, DFT calculations showed that the trans $\mathrm{NHC}$ which is a strong $\sigma$-donor ligand is able to stabilize the $\mathrm{Ru}=\mathrm{CRR}^{\prime}$ intermediate complex. 

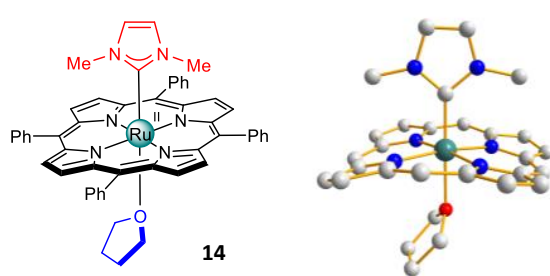

Figure 6. Left: structure of the mono(NHC) ruthenium(II) porphyrin complex 14 Right: X-ray crystal structure of complex 14. Hydrogen atoms and meso phenyl groups are omitted for clarity.

\subsection{Iron(III) Complexes}

More affordable transition metals such as iron(III) were also used to prepare $\mathrm{NHC}$ axially bonded metalloporphyrin complexes. Low-spin six-coordinate bis(NHC) iron(III) porphyrin complex 15 was prepared by Che and co-workers by reacting [Fe $\left.{ }^{\prime \prime \prime}(T D C P P)\right] O T f$ (TDCPP $=5,10,15,20$ - meso-tetrakis(2,6dichlorophenyl)porphyrin) with 1,3-dimethylimidazolium iodide in DMF (Scheme 5, top). ${ }^{[26]} \mathrm{X}$-ray diffraction analysis of complex 15 revealed a ruffled conformation of the porphyrin core and a $\sim 90^{\circ}$ torsion angle between the two NHC planes, similarly to the rhodium(III) complex 8 and the iridium(III) complex 12. The $\mathrm{C}_{\mathrm{NHC}^{-}}$ Fe"l' bond distances of $2.09 \AA$ and $2.08 \AA$ are significantly longer than $\mathrm{C}_{\text {carbene }}-\mathrm{Fe} \mathrm{e}^{\mathrm{ll}}$ bond distances of $1.83 \AA$ reported for both $\left[\mathrm{Fe}^{\prime \prime}(\mathrm{TPP})\left(\mathrm{CCl}_{2}\right)\left(\mathrm{OH}_{2}\right)\right]$ and $\left[\mathrm{Fe}^{\prime \prime}\left(\mathrm{F}_{20}-\mathrm{TPP}\right)\left(\mathrm{CPh}_{2}\right)(\mathrm{N}-\mathrm{Melmi})\right]$ complexes $(\mathrm{N}-\mathrm{Melmi}=\mathrm{N}$-methylimidazole $) \cdot{ }^{[27]}$

\section{Porphyrins with NHC on Meso Positions}

\subsection{Porphyrins with One NHC}

Imidazolyl or benzimidazolyl groups $\mathrm{N}$-linked to meso positions of porphyrins are possible intermediates to obtain porphyrins with NHC-metal complexes at their periphery. Some synthetic strategies were reported in the literature to obtain porphyrins with (benz)imidazolyl groups linked to the meso position by one of the nitrogen atoms. Smith and co-workers reacted imidazole as nucleophile with zinc(II) octaalkyporphyrin radical cation to produce the corresponding mesoimidazolylporphyrin. ${ }^{[28]}$ Aromatic nucleophilic substitution was also more recently used to introduce nitrogen nucleophiles at meso-bromoporphyrins. ${ }^{[29]}$ Devillers, Richeter and co-workers easily obtained a meso-imidazolylporphyrin by reacting a nickel(II) meso-nitroporphyrin complex with imidazole in basic conditions. ${ }^{[30]}$ Ruppert, Weiss and co-workers prepared meso(benz)imidazolylporphyrins by Ullmann coupling reaction between meso-bromotriarylporphyrins and (benz)imidazoles. ${ }^{[31]}$ Subsequent alkylation of the peripheral (benz)imidazolyl with iodoalkanes afforded the (benz)imidazolium salts, which could be used as NHC precursors. Reacting such porphyrins with $\mathrm{Pd}(\mathrm{OAc})_{2}$ in the presence of $\mathrm{KOtBu}$ allowed the synthesis of bis(NHC) palladium(II) complexes (Scheme 6).

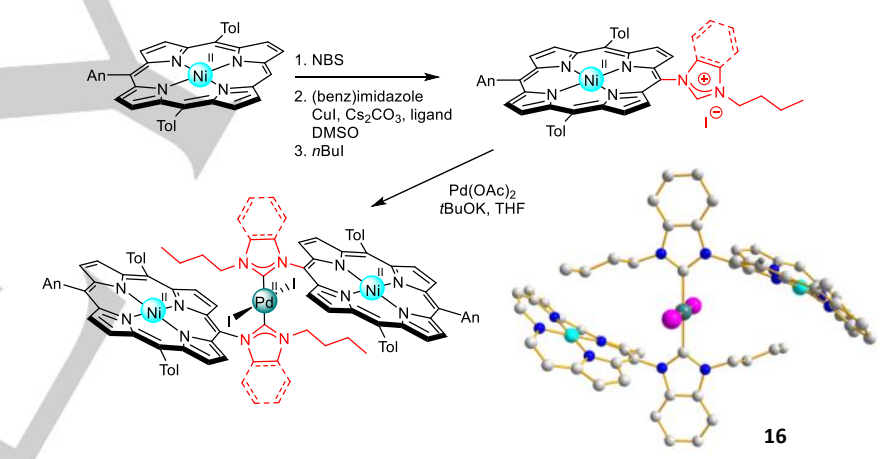

Scheme 6. Synthesis of bis(NHC) palladium(II) porphyrin complexes $(\mathrm{Tol}=p$ tolyl, $\mathrm{An}=p$-anisyl). Right: X-ray crystal structure of complex 16. Hydrogen atoms and meso aryl groups are omitted for clarity.

The X-ray structure of complex 16 with benzimidazol-2ylidene ligands was determined and revealed that the bis(NHC) palladium(II) square planar complex was the trans-anti isomer and that the two NHC ligands are nearly coplanar. The $\mathrm{Pd}-\mathrm{C}$ and Pd-I bonds distances are $\sim 2.01 \AA$ and $\sim 2.60 \AA$, respectively. The two porphyrins adopt ruffled deformations which are mainly attributed to the presence of nickel(II) ions in the macrocycles. Interestingly, electrochemical studies showed split oxidation waves which are usually observed for conjugated porphyrin dimers. As it is not the case here (meso NHC and porphyrin core mean plane are orthogonal), this effect may be attributed to intramolecular coulombic effects. Using the same kind of ligands, the bis(NHC) rhodium(I) complex was obtained by treating a meso-imidazolium porphyrin with $\left[\mathrm{Rh}(\mathrm{acac})(\mathrm{CO})_{2}\right]^{\left[{ }^{[32]}\right.}$ The obtained square planar bis $(\mathrm{NHC})$ rhodium(I) complex with one iodide and one $\mathrm{CO}$ ligand $\left(v_{\mathrm{CO}}=1943 \mathrm{~cm}^{-1}\right)$ is chiral and, as a consequence, protons of the $\mathrm{CH}_{2}$ groups are diastereotopic. 
In addition to (benz)imidazol-2-ylidenes, Ruppert, Weiss and co-workers also reported the synthesis of metal complexes with other types of NHC ligands on meso positions of porphyrins (Scheme 7). ${ }^{[32]}$ For example, following a similar synthetic procedure using the Ullmann coupling reaction, the authors prepared a nickel(II) meso 1,2,4-triazolyl-substituted porphyrin, which was subsequently alkylated to obtain the corresponding 1,2,4-triazolium-substituted porphyrin salt. The corresponding bis(NHC) palladium(II) complex 17 was obtained by reacting the triazolium salt with $\mathrm{Pd}(\mathrm{OAc})_{2}$ and $\mathrm{KO}$ tBu. X-ray diffraction analysis also revealed the trans-anti geometry of the square planar palladium(II) complex. The $\mathrm{Pd}-\mathrm{C}$ and $\mathrm{Pd}-\mathrm{I}$ bond distances of $2.010 \AA$ and $2.605 \AA$, respectively, are similar to those observed for the corresponding complex 16. By reacting a mesoazidoporphyrin with phenylacetylene under click chemistry conditions, Ruppert, Weiss and co-workers also synthesized the nickel(II) meso 1,2,3-triazole-substituted porphyrin. The triazolium salt obtained after the alkylation reaction was used as an abnormal NHC precursor to obtain the corresponding rhodium(I) complexes 18 and 19.

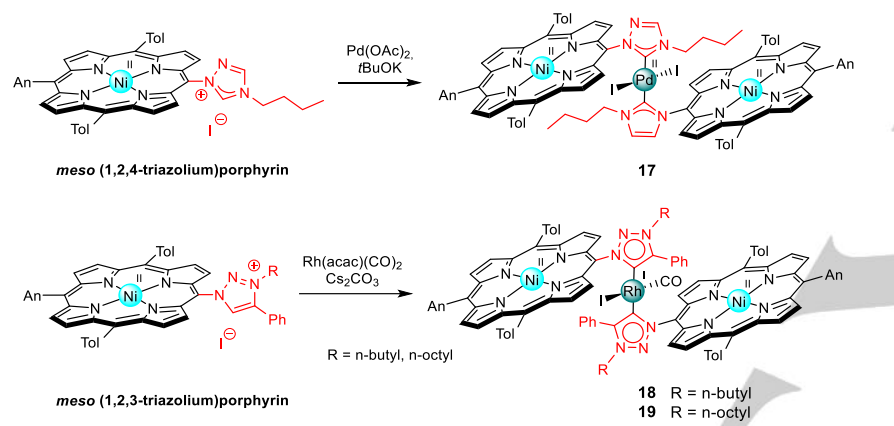

Scheme 7. Synthesis of bis(NHC) palladium(II) and rhodium(I) porphyrin complexes 17-19 $(\mathrm{Tol}=p$-tolyl, $\mathrm{An}=p$-anisyl).

\subsection{Porphyrins with Four NHC}

Cage-like structures containing two porphyrins assembled face-to-face are useful compounds for diverse applications such as encapsulation of guest molecules or energy transfer studies. ${ }^{[33]}$ Cofacial porphyrin dimers are also investigated as catalysts notably for small molecule activation reactions such as $\mathrm{O}_{2}$ or $\mathrm{CO}_{2}$ reduction reactions. ${ }^{[34]}$ Most of the cofacial porphyrin dimers selfassembled from metal-ligand bonds are Werner-type complexes because labile bonds like O-M or N-M are needed to allow selfcorrection. Such self-assembly strategy is also feasible with $\mathrm{NHC}$ ligands when considering $\mathrm{C}_{\mathrm{NHC}}-\mathrm{Ag}^{\prime}$ bonds which are labile. ${ }^{[35]}$ Indeed, Richeter and co-workers reported the synthesis of porphyrin 20 equipped with imidazolium salts on the para positions of the four meso aryl groups. These imidazolium salts were used as NHC precursors for the synthesis of cofacial porphyrin dimer $\mathbf{2 1}$ self-assembled from eight $\mathrm{C}_{\mathrm{NHC}}-\mathrm{Ag}^{\prime}$ bonds (Scheme 8). ${ }^{[36]}$ Blue-shifted Soret absorption band relative to the one of [Zn(TPP)] used as a reference was in agreement with the cofacial orientation of the porphyrins. The lability of the $\mathrm{C}_{\mathrm{NHC}}-\mathrm{Ag}$ bonds allowed the transmetalation of the NHCs from $\mathrm{Ag}^{+}$to $\mathrm{Au}^{+}$ and the formation of cofacial porphyrin dimer 22 with improved stability due to the formation of strong $\mathrm{C}_{\mathrm{NHC}}-\mathrm{Au}^{\prime}$ bonds (Scheme 8). The single ${ }^{13} \mathrm{C}\left\{{ }^{1} \mathrm{H}\right\}$ carbene NMR signal observed at $\delta=181.7$ ppm and the expected signal observed at $m / z=696.1199$ Da by mass spectrometry confirmed the effective substitution of the four $\mathrm{Ag}^{\mathrm{l}}$ ions by $\mathrm{Au}^{\prime}$.

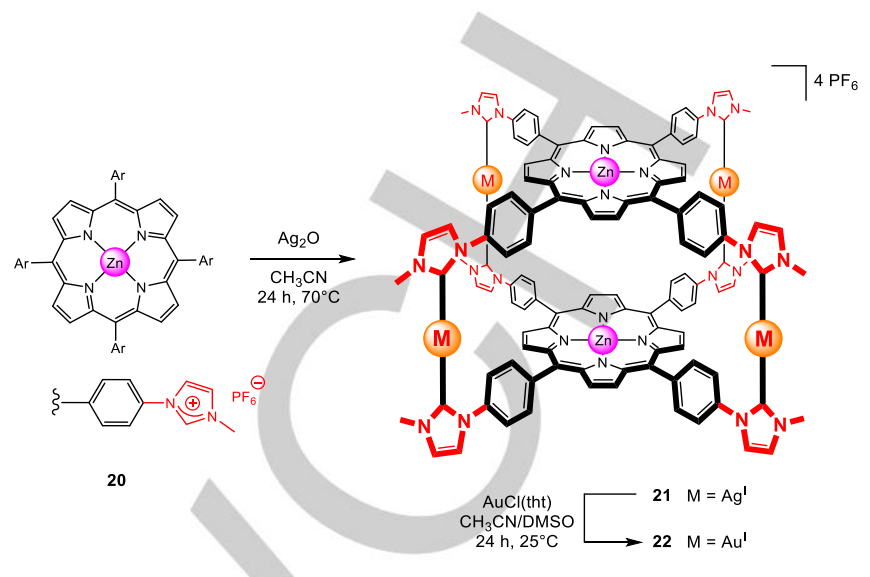

Scheme 8. Synthesis of cofacial porphyrin dimers 21 and 22. tht = tetrahydrothiophene.

\section{Porphyrins Fused to NHC}

\subsection{Porphyrins Fused to One Imidazolium Ring}

Porphyrins fused to $\mathrm{NHC}$ across two neighboring $\beta$-pyrrolic positions are probably the most investigated systems combining porphyrins and NHCs for different applications. These ligands were first reported in 2007 by Richeter and co-workers and

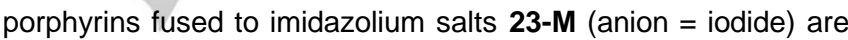
key NHC precursors. ${ }^{[37]}$ These porphyrins were obtained in five steps starting from the corresponding non-functionalized meso

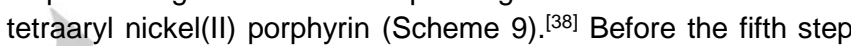
which is the alkylation of the porphyrin-imidazole, it is possible to remove the nickel(II) ion (TFA/ $\left.\mathrm{H}_{2} \mathrm{SO}_{4} 4: 1\right)$ and to metalate the porphyrin macrocycle with another metal ion such as zinc(II), copper(II) or manganese(III), for examples. The corresponding free-base porphyrin-imidazole was also isolated although it is not very stable due to electron-rich imidazole ring photooxidation affording a secochlorin derivative. ${ }^{[39]}$ In contrast, after alkylation, the electron-deficient corresponding free-base porphyrin imidazolium salt is very stable towards photooxidation. X-ray crystal structure of imidazolium salt $\mathbf{2 3 - 2} \mathbf{H}$ is displayed in Scheme 10. Interestingly, the porphyrin core is not flat and adopts a saddle-shape distorted geometry. Moreover, the iodide counterion is hydrogen bonded to the $\mathrm{C}-\mathrm{H}$ of the peripheral imidazolium ring. ${ }^{[40]}$ Imidazolium salts 24-M (anion = tetrafluoroborate) could be obtained after anion metathesis reaction with $\mathrm{AgBF}_{4}$. 


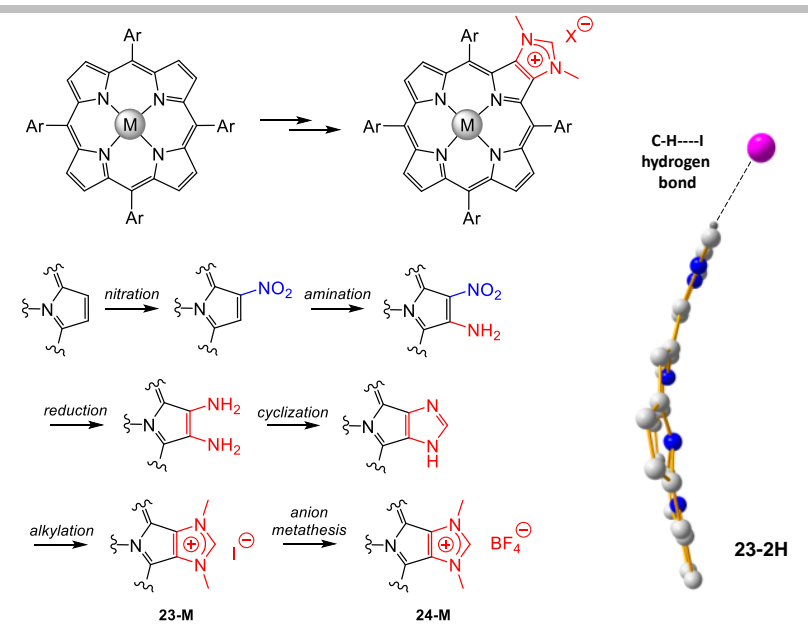

Scheme 9. Synthetic strategy to obtain porphyrins fused to imidazolium salts 23-M and 24-M ( $\mathrm{Ar}=4$ 4-tBuPh). Right: $\mathrm{X}$-ray structure of the free-base porphyrin fused to 1,3-dimethylimidazolium salt $\mathbf{2 3 - 2 H}$. Hydrogen atoms and meso aryl groups are omitted for clarity.

\subsection{Rhodium(I) Complexes and Modulation of the NHC Donicity}

Modulation of the electronic properties of NHCs is feasible by functionalizing the $\mathrm{N}$-heterocycle with electron-donating or electron-withdrawing groups. However, synthesis of such ligands is not always trivial and, most of the time, requires the synthesis of new $\mathrm{NHC}$ precursors with fixed electronic properties. Therefore, $\mathrm{NHCs}$ allowing the reversible and controlled switching of their electronic properties between electron-poor and electron-rich states attracted attention. ${ }^{[11]}$ Photoswitchable, redox-active and $\mathrm{pH}$-sensitive NHC ligands are examples of switchable NHCs. ${ }^{[42]}$ Coordination of metal complexes to an adjacent coordination site can also modulate the electronic properties of $\mathrm{NHC}$ ligands. ${ }^{[43]} \mathrm{All}$ these switchable NHCs incorporate stimuli-responsive subunits in their backbone. Porphyrins can be considered as stimuli responsive units which can modulate the electronic properties of the fused peripheral NHC ligand. To evaluate the electronic properties of porphyrins fused to $\mathrm{NHC}$ ligands, square planar rhodium(I) complexes displayed in Scheme 10 were synthesized. Imidazolium salts 24-M (anion = tetrafluoroborate) were used as $\mathrm{NHC}$ precursors to obtain rhodium(I) complexes 25-M and 26-M (Scheme 10). ${ }^{[44]}$ The CO ligands of complexes $26-\mathbf{M}$ can be used as probes to evaluate the electronic properties of the peripheral $\mathrm{NHC}$ through IR spectroscopy: the more electron-donating NHC, the longer the $\mathrm{CO}$ bond, and the lower the $\mathrm{CO}$ stretching frequency. This is due to increased electron-density into the $\pi^{*}$ co through $\pi$-backbonding interaction from the rhodium(I) to the CO. ${ }^{[45]}$ The ability of the porphyrin to modulate the electronic properties of its peripheral NHC was evaluated by monitoring $v(\mathrm{CO})$ vibrations. For the neutral free-base porphyrin derivative 26-2H in $\mathrm{CH}_{2} \mathrm{Cl}_{2}$, the $v(\mathrm{CO})$ vibrations were found to be 2002 and $2080 \mathrm{~cm}^{-1}$ (average $v(\mathrm{CO})=2041 \mathrm{~cm}^{-1}$ ). The addition of a Brönsted acid like trifluoroacetic acid (TFA) to a solution of $\mathbf{2 6 - 2 H}$ in $\mathrm{CH}_{2} \mathrm{Cl}_{2}$ caused an immediate change of color from purple to green due to the protonation of the inner nitrogen atoms. The two carbonyl stretching frequencies observed by FT-IR spectroscopy were found to be 2010 and $2089 \mathrm{~cm}^{-1}$ (average $v(C O)=2049.5$ $\left.\mathrm{cm}^{-1}\right)$. The higher $v(\mathrm{CO})$ vibrations clearly show the weaker electron-donating ability of the NHC belonging to complex 26$4 \mathrm{H}^{2+}$, which is attributed to the strong electron withdrawing effect caused by the positive charges inside the cavity. The process is

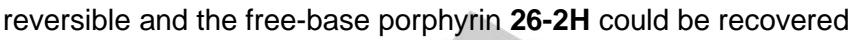
by addition of a base. Such behaviour was not observed when nickel(II) is in the porphyrin macrocycle (complex 26-Ni"), as the presence of nickel(II) prevents the protonation of the inner nitrogen atoms. Moreover, porphyrin nickel(II) complexes are very stable towards acidic conditions. Consequently, nickel(II) locks the $\mathrm{NHC}$ on its electron-rich state since the $v(\mathrm{CO})$ vibrations were found to be 2002 and $2081 \mathrm{~cm}^{-1}$ (average $v(C O)=2041.5 \mathrm{~cm}$ 1). ${ }^{[44]}$

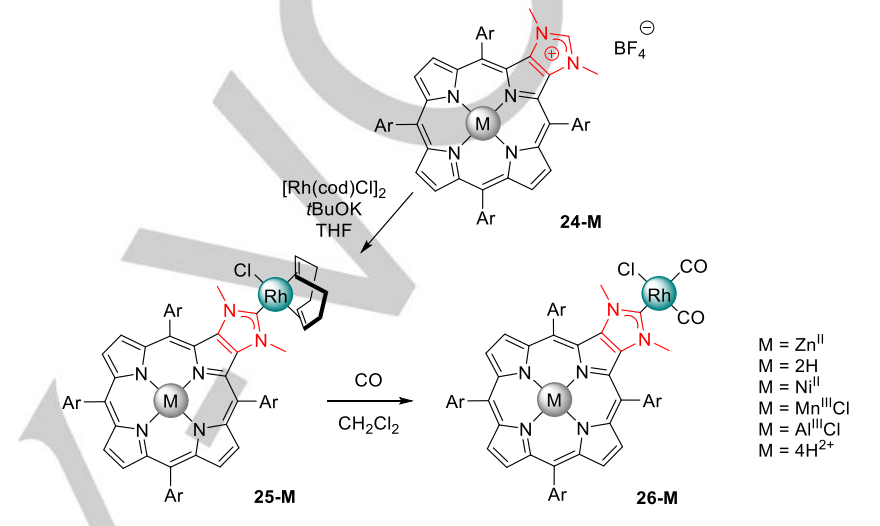

Scheme 10. Synthesis of rhodium(I) complexes 25-M and 26-M.

Table 1. CO stretching frequencies of rhodium(I) complexes 26-M ${ }^{[a]}$

\begin{tabular}{|c|c|c|c|c|c|c|}
\hline $\mathbf{M}$ & $Z n^{\prime \prime}$ & $2 \mathrm{H}$ & Nill & $\mathrm{Mn}^{\mathrm{III} \mathrm{Cl}}$ & $\mathrm{Al}^{\mathrm{II} \mathrm{Cl}}$ & $4 \mathrm{H}^{2+}$ \\
\hline$v \mathrm{co}$ & 2080 & 2080 & 2081 & 2084 & 2084 & 2089 \\
\hline$\left(\mathrm{cm}^{-1}\right)$ & 2001 & 2002 & 2002 & 2004 & 2005 & 2010 \\
\hline $\begin{array}{l}v c o \text { av } \\
\left(\mathrm{cm}^{-1}\right)\end{array}$ & 2040.5 & 2041 & 2041.5 & 2044 & 2044.5 & 2049.5 \\
\hline
\end{tabular}

[a] Measured in $\mathrm{CH}_{2} \mathrm{Cl}_{2}$. av : average. From the left to the right, the $\sigma$-donnor character of $\mathrm{NHCs}$ decreases.

Noteworthy, electronic properties of the peripheral NHC can be finely tuned according to the nature of the porphyrin inner metal cation (Table 1). Divalent and trivalent metal cations such as nickel(II), zinc(II), manganese(III) and aluminum(III) were included in the porphyrin macrocycle to study how electronic properties of the peripheral NHC could be affected by the valence of the inner metal ion. ${ }^{[46]}$ Rhodium(I) complexes 26-M containing porphyrins with divalent metal cations such as nickel(II) or zinc(II) present similar $v(\mathrm{CO})$ which are comparable to data obtained for free-base derivative $\mathbf{2 6 - 2 \mathrm { H }}$. When trivalent metal cations such as $\mathrm{Mn}{ }^{\mathrm{III}} \mathrm{Cl}$ and $\mathrm{Al}{ }^{\mathrm{II}} \mathrm{Cl}$ are inserted in the porphyrin core, $v(\mathrm{CO})$ stretching frequencies are significantly higher showing that corresponding $\mathrm{NHCs}$ are weaker electron-donors. NHC ligand

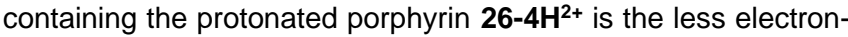
donor of the series. The average $\Delta v(\mathrm{CO})$ between the most electron-rich $\mathrm{NHC}$ ( $\mathrm{Zn}^{\|}$porphyrin) and the most electron-poor $\mathrm{NHC}$ (protonated porphyrin) is $9 \mathrm{~cm}^{-1}$. 


\subsection{Free NHCs as Organocatalysts for the Ring Opening Polymerization of L-Lactide}

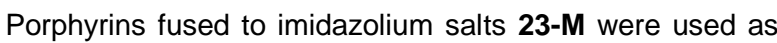
$\mathrm{NHC}$ precursors to catalyse the synthesis of Poly-L-Lactic Acid (PLA) by Ring Opening Polymerization (ROP) of L-Lactide (L-LA) (Scheme 11). ${ }^{[45]}$ In the conditions described in Table 2, the number-averaged PLA molecular weights $\left(M_{n}\right)$ obtained with each catalyst vary linearly with conversion. Moreover, the dispersity $\left(\Theta_{\mathrm{M}}\right)$ values determined by Size Exclusion Chromatography (SEC) are within the range of 1.03-1.60. These obtained data demonstrate that the studied polymerization reactions are wellcontrolled. More interestingly, the porphyrin inner metal has a significant impact on the outer $\mathrm{NHC}$ reactivity which increases in the order $\mathbf{M n}^{\text {"I' }} \mathbf{C l}<<\mathbf{N i "}<\mathbf{2} \mathbf{H}<\mathbf{Z n}{ }^{\prime \prime}$. Indeed, the fastest $\mathrm{ROP}$ reaction was observed with the most electron-rich $\mathrm{NHCs}$ (i.e. containing the most electron-rich $\mathrm{Zn}$ " porphyrin $\pi$ system) and vice versa. Other phenomena such as catalyst aggregation and axial coordination of additional ligands can also affect the catalytic properties of peripheral NHCs.

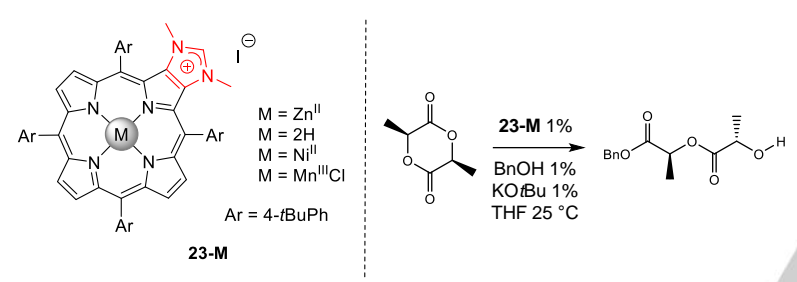

Scheme 11. Ring-Opening Polymerization (ROP) reactions catalysed by in situ generated $\mathrm{NHC}$ when using porphyrin-imidazolium salts 23-M as $\mathbf{N H C}$ precursors.

Table 2. Properties of poly(L-Lactide)s obtained by ROP reactions catalysed by in situ generated porphyrin-NHC when using porphyrin-imidazolium salts 23-M as NHC precursors. ${ }^{[a]}$

\begin{tabular}{|c|c|c|c|c|}
\hline $\mathbf{M}^{[\mathrm{b}]}$ & $t[h]$ & conv [\%] & $M_{\mathrm{n}}\left[\mathrm{g} \mathrm{mol}^{-1}\right]^{[\mathrm{c}]}$ & $\boldsymbol{E}_{\mathrm{M}}[\mathrm{c}]$ \\
\hline \multirow[t]{2}{*}{$Z^{\prime \prime}$} & 0.33 & 83 & 15500 & 1.17 \\
\hline & 0.58 & 93 & 17000 & 1.12 \\
\hline $2 \mathrm{H}$ & 0.83 & 86 & 16000 & 1.20 \\
\hline \multirow[t]{2}{*}{ Nill } & 0.83 & 23 & 4100 & 1.20 \\
\hline & 3.33 & 93 & 17000 & 1.60 \\
\hline \multirow[t]{4}{*}{ Mn"'CI } & 0.33 & 6 & 1000 & 1.03 \\
\hline & 1.00 & 10 & 1900 & 1.04 \\
\hline & 3.17 & 18 & 3350 & 1.14 \\
\hline & 6.00 & 27 & 4200 & 1.16 \\
\hline
\end{tabular}

[a] The reactions were performed in THF with $\mathrm{BnOH}$ as initiator. $\mathrm{L}-\mathrm{LA}=2 \mathrm{M}$, [L$\mathrm{LA}]_{0} /[\mathrm{BnOH}]_{0} /[\mathrm{NHC}]_{0}=100: 1: 1$. [b] The $\mathrm{NHC}$ was generated in situ by deprotonating the imidazolium salts 23-M with $\mathrm{KO}$ tBu. [c] Determined by SEC in $\mathrm{CHCl}_{3}$ at $35^{\circ} \mathrm{C}$ by using polystyrenes standards.

\subsection{Palladium(II) Complexes as Precatalysts for the Mizoroki-Heck Reaction}

Besides organocatalysis, palladium(II) complexes were synthesized and used as precatalysts in Mizoroki-Heck coupling reactions (Scheme 12). ${ }^{[47]}$ Reaction of 0.5 equivalent of $\mathrm{Pd}(\mathrm{OAc})_{2}$ with porphyrins 23-M afforded a mixture of the two palladium(II) complexes 27-M and 28-M in a molar ratio of $\sim 4: 1$. The yields of complexes 28-M could be significantly increased by adding $\mathrm{Nal}$ to the reaction mixture and by using one equivalent of $\mathrm{Pd}(\mathrm{OAc})_{2}$. The X-ray crystal structure of the homoleptic bis(NHC) palladium(II) complex 27-Ni was obtained and showed that palladium(II) adopts a trans square planar geometry (Figure 7). ${ }^{[37]}$ The $\mathrm{Pd}-\mathrm{C}$ and $\mathrm{Pd}-\mathrm{I}$ bonds distances are $\sim 2.03 \AA$ and $\sim 2.59 \AA$, respectively (which are very similar to the distances observed for complex 16). The two NHC ligands are almost coplanar with a tilted angle of $\sim 82^{\circ}$ relative to the square planar central plan $\mathrm{Pdl}_{2} \mathrm{C}_{2}$. Absorption bands in the UV-visible spectra of palladium(II) complexes $\mathbf{2 7 - M}$ are only slightly broadened and red-shifted compared to those of the corresponding monomers 23-M. Moreover, there is no splitting of the oxidation or reduction waves observed by electrochemistry suggesting that there is no or negligible ground state electronic communication between the two porphyrins through the palladium(II) bridge. This can be attributed to a lack of frontier molecular orbital overlap between the two porphyrins and a lack of palladium(II) atomic contribution to the $\pi$-system. ${ }^{[48]}$ 
Bridged $\left[\{\mathrm{PdI}(\mu-\mathrm{I})(\mathrm{NHC})\}_{2}\right]$ complexes 28-M were used as precatalysts for the Mizoroki-Heck coupling reaction between iodobenzene and styrene. The data obtained clearly showed that coupling reactions catalysed by complexes containing metalated porphyrins are much faster than the coupling reaction catalysed by the precatalyst containing free-base porphyrins $\mathbf{2 8 - 2 H}(80$ $90 \%$ conversions vs. $30 \%$ after 10 hours of reaction). In this case, control experiments showed that the free-base porphyrins are able to trap palladium(II) ions issued from the decomposition of precatalyst $\mathbf{2 8 - 2 H}$. This is not the case with precatalysts containing metalated porphyrins, because inner metal ions in the porphyrin macrocycles act as "protecting groups" preventing the trapping of leached palladium species involved in the catalytic reaction. In fact, poisoning experiments with mercury and Transmission Electronic Microscopy (TEM) images showed that palladium nanoparticles are generated in the reaction mixture which are involved in the catalytic reactions. Indeed, precatalysts 28-M can be considered as reservoirs of palladium species for the Mizoroki-Heck coupling reactions.

\subsection{Dyads Assembled by Palladium(II) Complexes}

In Nature, chlorophylls and bacteriochlorophylls of photosynthetic systems are able to transfer energy and/or electrons upon light irradiation with high efficiencies and rates. To mimic these natural systems and understand the involved processes, many donor-acceptor (D-A) systems with different geometries, orientations and distances between the chromophores were studied. Examples of dyads using transitionmetal complexes as bridging units in D-A assemblies remain relatively scarce compared to covalently linked systems. ${ }^{[48,49]}$ One of the main difficulties is to functionalize one metal complex with two different types of chromophores having the required properties to obtain D-A systems. Knowing that zinc(II) and freebase porphyrins can be used as donors and acceptors, respectively, such a dyad, namely the heteroleptic bis(NHC) palladium(II) complex 29, was obtained with porphyrins fused to NHC ligands (Scheme 13). ${ }^{[48]}$ One of the easiest procedures to obtain the dyad 29 consists in reacting the homoleptic bis $(\mathrm{NHC})$ palladium(II) complex 27-2H with one equivalent of $\mathrm{Zn}(\mathrm{OAc})_{2}$ to obtain a statistical mixture of compounds containing the expected dyad 29 (38\% isolated yield) accompanied with the two homoleptic bis(NHC) palladium(II) complexes $27-2 \mathrm{H}$ and $\mathbf{2 7 - Z n}$ (Scheme 13, left). Alternatively, the dyad 29 could be obtained in $41 \%$ yield by reacting one equivalent of the bridged $[\operatorname{PdI}(\mu$ I) $(\mathrm{NHC})\}_{2}$ ] complex 28-2H with one equivalent of the imidazolium salt $\mathbf{2 3 - Z n}$ and a base (Scheme 13, right). $S_{1}$ energy transfer between $D$ and $A$ within the dyad 29 was investigated. Relatively slow energy transfer rates of $\sim 90-330$ ps were measured. ${ }^{[48]}$ DFT calculations clearly show the lack of frontier molecular orbital overlap between the $D$ and the $A$ due to the lack of $\mathrm{Pd}^{\text {II }}$ atomic contributions to the $\pi$-system. Such overlapping deficiency necessarily limits the energy transfer process to a Förster Resonance Energy Transfer (FRET) mechanism. The slow energy transfer rate may also be explained by the presence of the two electron-rich iodide ligands screening the $D$ and the $A$ transition moments.

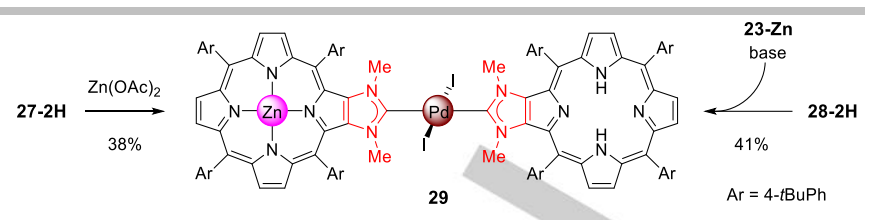

Scheme 13. Synthetic strategies to obtain the dyad 29

\subsection{Gold Complexes for Photodynamic Therapy}

Porphyrins fused to NHC ligands were used for the synthesis of mono- and bis(NHC) gold(I) complexes (Scheme 14). ${ }^{[40]}$ Mono(NHC) gold(I) complexes $30-\mathbf{M}$ could be obtained in

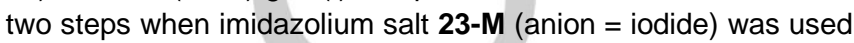
as starting material: the corresponding mono(NHC) silver(I) complexes were first synthesized with $\mathrm{Ag}_{2} \mathrm{O}$ and gold(I) complexes $\mathbf{3 0}-\mathbf{M}$ were obtained by a transmetalation reaction of the $\mathrm{NHC}$ with $[\mathrm{AuCl}(\mathrm{tht})]$ (tht = tetrahydrothiophene). Alternatively, gold complexes $\mathbf{3 0 - M}$ could be obtained in one step by reacting the imidazolium salts $\mathbf{2 4 - M}$ (anion = tetrafluoroborate) with $[\mathrm{AuCl}(\mathrm{tht})]$ in the presence of a base. X-ray crystal structure of the gold(I) complex $\mathbf{3 0 - Z n}$ with pyridine as axial ligand is represented in Scheme 14..$^{[5]}$ As expected, it shows that gold(I) complex adopts a linear geometry (C-Au-Cl angle is $\left.\sim 177.5^{\circ}\right)$. The two Au$\mathrm{C}$ and $\mathrm{Au}-\mathrm{Cl}$ distances of $\sim 2.02$ and $\sim 2.29 \AA$ are in agreement with those reported in the literature. ${ }^{[35]}$ Cationic bis-NHC gold(I) complexes $\mathbf{3 1 - M}$ were obtained by substituting chloride ligand of

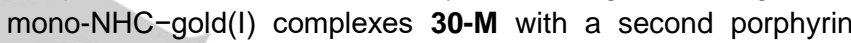
$\mathrm{NHC}$ ligand (Scheme 14, bottom). Homoleptic and heteroleptic bis(NHC) gold(I) complexes could be obtained following this procedure. ${ }^{[40]}$
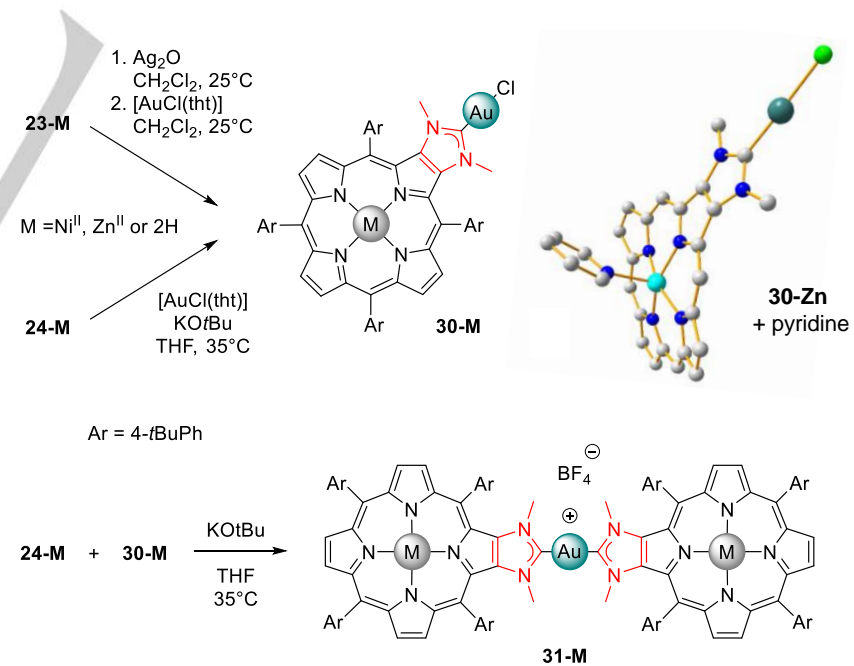

Scheme 14. Synthesis of gold(I) complexes $\mathbf{3 0 - M}$ and 31-M. X-ray crystal structure of complex $\mathbf{3 0 - Z n}$ with pyridine as axial ligand. Hydrogen atoms and meso aryl groups are omitted for clarity.

These gold(I) complexes, notably mono(NHC) gold(I) complexes, were used for applications in photodynamic therapy (PDT). ${ }^{[50]}$ Interestingly, photophysical studies showed that the gold(I) complex $\mathbf{3 0 - 2 H}$ with a free-base porphyrin is a better photosensitizer for PDT in comparison to the corresponding imidazolium salt. This may be attributed to the "heavy atom" effect 
of the peripheral $\mathrm{Au}(\mathrm{I})$ complex promoting the intersystem crossing $S_{1} \rightarrow T_{1}$ which consequently increases generation of ${ }^{1} \mathrm{O}_{2} \cdot{ }^{[40]}$ To improve water solubility, bioavailability and active targeting of cancer cells, the chloride ligand of mono(NHC) gold $(\mathrm{I})$ complex $\mathbf{3 0 - 2 H}$ was substituted by a thiolate ligand bearing an unprotected $\alpha$-D-mannose group to obtain compound $\mathbf{3 2}$ (Scheme 15). Photodynamic activity of the gold(I) complex 32 was evaluated on MCF-7 cancer cells which are known to overexpress mannose receptors. The results obtained with compounds $\mathbf{3 2}$ and 33 (a similar gold(I) complex without the mannose unit) clearly showed the crucial role played by the mannose unit in the active endocytosis of complex $\mathbf{3 2}$ in MCF-7 cancer cells as well as the improved photodynamic effect. ${ }^{[50]}$

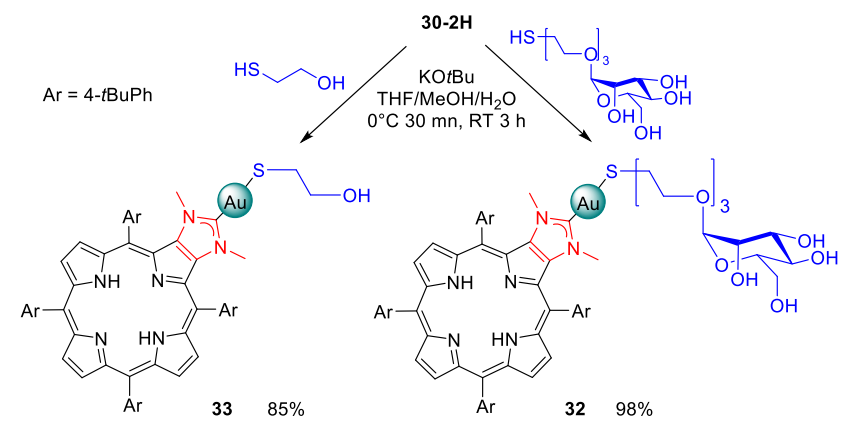

Scheme 15. Synthesis of gold(I) complexes 32 and 33 . leaching could be observed in toluene after irradiation suggesting the good stability of the porphyrin-based MCOPs for photocatalytic applications.

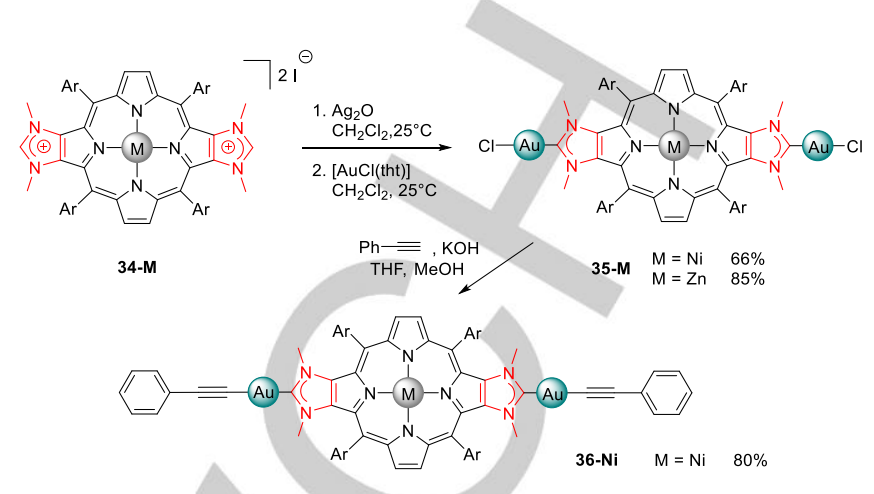

Scheme 16. Synthesis of gold (I) complexes 35-M and 36-Ni.

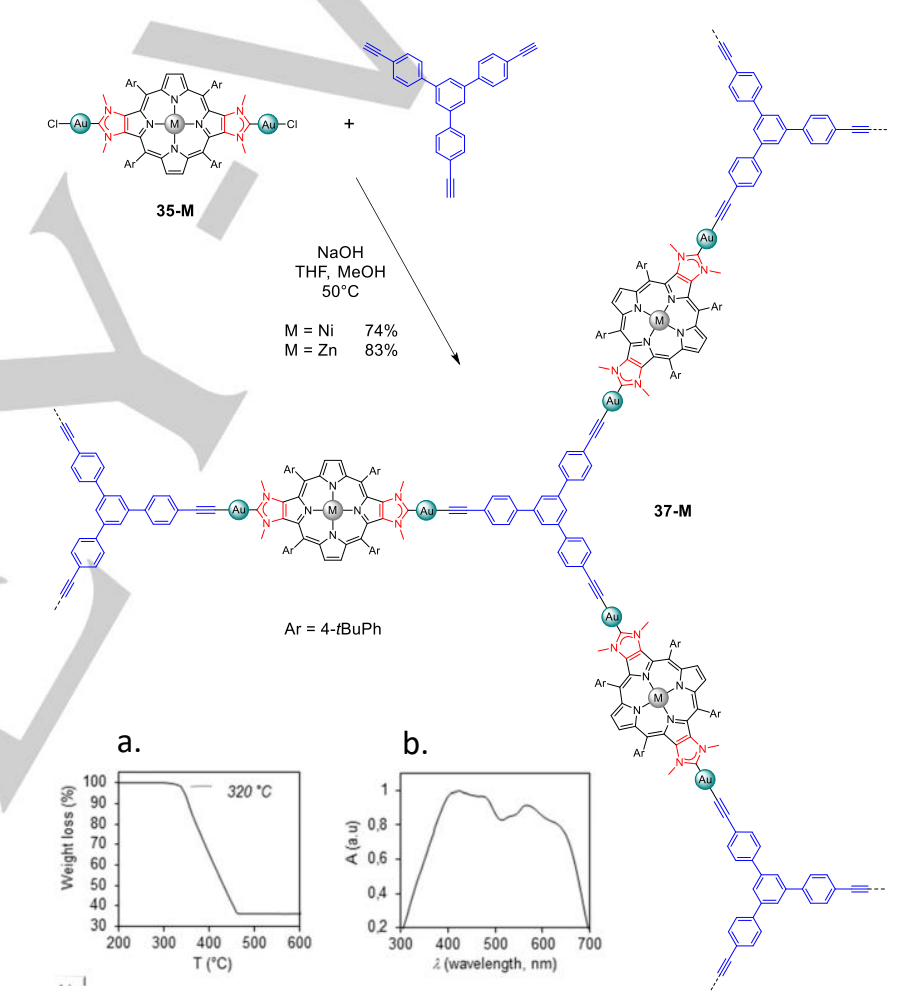

Scheme 17. Synthesis of main-chain organometallic polymers 37-M. Inset: (a) Thermogravimetric analysis (TGA); (b) Solid state UV-Visible absorption spectrum of $\mathbf{3 7 - Z n}$

\section{Other Porphyrinoids}

\subsection{N-Confused Porphyrins}

$\mathrm{N}$-confused porphyrins are porphyrin isomers containing one or more inverted pyrrole rings connected to the surrounding meso carbons at the $\alpha$ - and $\beta$-positions. Consequently, one $\beta$ - $\mathrm{CH}$ is pointing inside the porphyrin cavity and a carbon-metal bond is formed upon complexation of metal ion in the inner core. As for the outer nitrogen atom, it can be used as a peripheral coordination site. Thus, $\mathrm{N}$-confused porphyrins are interesting 
porphyrinoids with unusual coordination abilities and different reactivity compared to porphyrins. In the course of their studies on the functionalization of $\mathrm{N}$-confused porphyrins, Furuta and coworkers serendipitously synthesized rhenium(I) complexes of $\mathrm{NHC}$ ligands embedded in the macrocycles (Scheme 18). ${ }^{[54]}$ Complex 39 was prepared in $25 \%$ conversion yield by the thermal reaction of the 22-methylated $\mathrm{N}$-confused porphyrin 38 with $\mathrm{Re}_{2}(\mathrm{CO})_{10}$ in 1,2 dichlorobenzene at $140^{\circ} \mathrm{C}$ for 16 hours. X-ray crystallographic structure of complex 39 showed that rhenium(I) is coordinated by the embedded 6-membered ring NHC ligand as well as three $\mathrm{CO}$ ligands and two nitrogen atoms of the $\mathrm{N}$ confused porphyrin core. The Re'-C bond length of $2.14 \AA$ is within the range of other $\mathrm{Re}^{\mathrm{l}}-\mathrm{C}_{\mathrm{NHC}}$ bond lengths reported in the literature. Alternatively, the reaction of 21-methylated $\mathrm{N}$-confused porphyrin $\mathbf{4 0}$ under similar reaction conditions afforded complex $\mathbf{4 1}$ in $18 \%$ yield together with complex 39 in $6.1 \%$ yield. Peripherally $\pi$ extended $\mathrm{N}$-confused porphyrin rhenium complexes with embedded NHC-rhenium(I) complexes were also reported by Furuta and co-workers. ${ }^{[55]}$

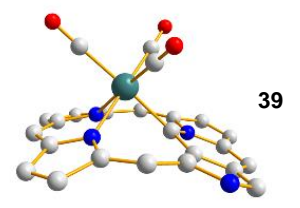

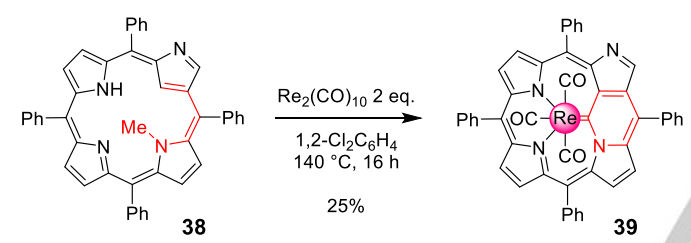

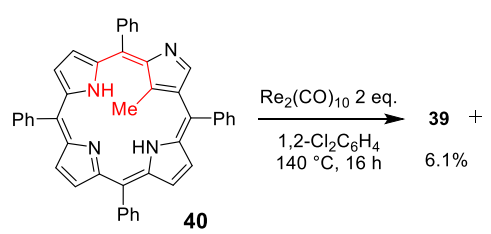

40

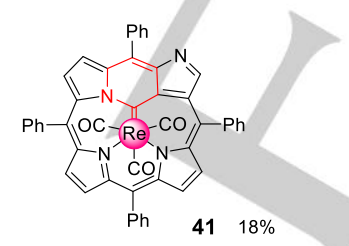

Scheme 18. Synthesis of $\mathrm{NHC}-\mathrm{Re}(\mathrm{I})(\mathrm{CO})_{3}$ complexes 39 and 41 embedded in an $\mathrm{N}$-confused porphyrin. X-ray structure of complex 39 . Hydrogen atoms and meso phenyl groups are omitted for clarity.

Chmielewski, $\mathrm{Li}$ and co-workers used the outer nitrogen atom of $\mathrm{N}$-confused porphyrins for the construction of peripheral imidazole ring. ${ }^{[56]}$ Indeed, imidazole-fused carbachlorin $43-2 \mathrm{H}$ was obtained in one step by reacting the corresponding free-base $\mathrm{N}$-confused porphyrin $\mathbf{4 2}$ with tosylmethylisocyanide (TOSMIC) and $\mathrm{KOH}$ in refluxing THF for 12 hours. Complexation of imidazole-fused carbachlorin $\mathbf{4 3 - 2 \mathrm { H }}$ with $\mathrm{CF}_{3} \mathrm{CO}_{2} \mathrm{Ag}$ (silver disproportionation) to the corresponding silver(III) complex 43-Ag and subsequent alkylation of the peripheral imidazole with $\mathrm{CH}_{3} \mathrm{I}$ afforded the corresponding imidazolium salt 44. This compound was used as NHC precursor for the synthesis of mono-NHC gold(I) complex 45 as reported in Scheme 19. X-ray diffraction analysis of complex $\mathbf{4 5}$ showed that the $\mathrm{Au}-\mathrm{C}$ and $\mathrm{Au}-\mathrm{Cl}$ distances of $\sim 2.00$ and $\sim 2.29 \AA$ are close to those reported for complex 30$\mathrm{Zn}$. The gold(I) complex adopts a nearly linear geometry (C-Au$\mathrm{Cl}$ angle is about $\left.\sim 175.1^{\circ}\right)$. An interesting structural feature observed for compound $\mathbf{4 5}$ is the close proximity between the
gold(I) atom and the neighbouring meso-phenyl ring ( $\mathrm{Au}-\mathrm{Ph}_{\text {centroid }}$ $\sim 3.19 \AA$ and closest $\mathrm{Au}-\mathrm{C}_{\mathrm{Ph}}$ contact $\sim 3.16 \AA$ ) indicating a weak interaction between the gold $(I)$ complex and the phenyl substituent.

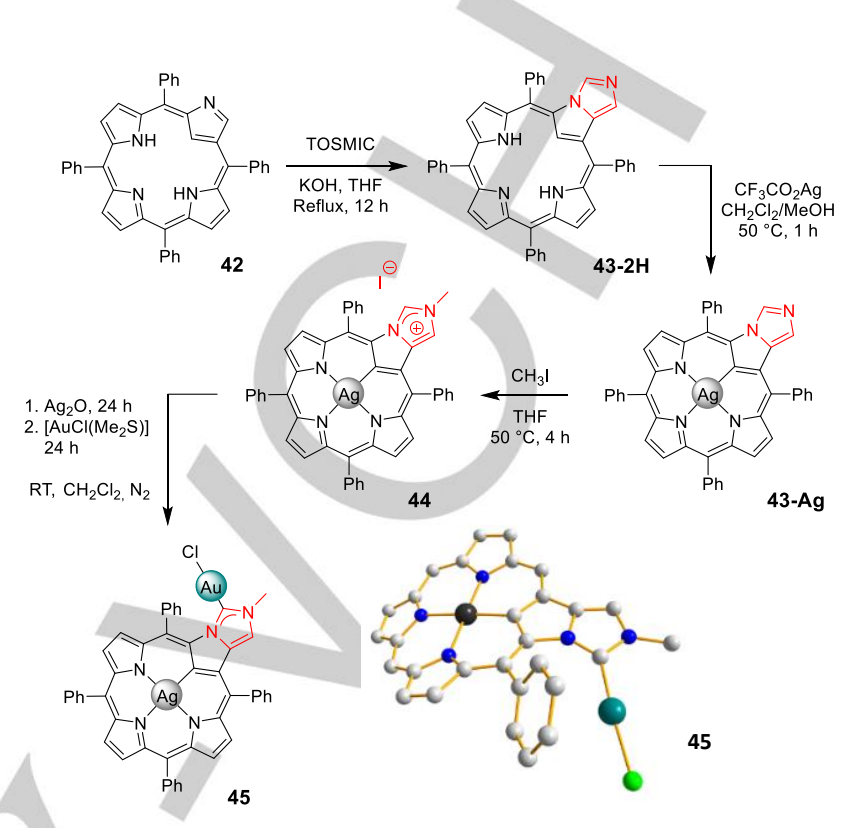

Scheme 19. Synthesis of NHC-Au(I) complex 45 fused with a $\mathrm{N}$-confused porphyrin. X-ray crystal structure of complex 45. Hydrogen atoms and meso phenyl groups are omitted for clarity except the phenyl group beside the NHC$\mathrm{Au}(\mathrm{I})$ complex.

\subsection{Subporphyrins}

Boron(III) subporphyrins are $14 \pi$ electron ring-contracted porphyrin derivatives with a bowl-shaped structure featuring interesting properties compared to porphyrins such as bright fluorescence. In the course of their studies on pyrrole-modified subporphyrin derivatives, Osuka and co-workers reported the synthesis of subporpholactone, subporpholactam and imidazolosubporphyrin. ${ }^{[57]}$ The structure of imidazolosubporphyrin 46 is represented in Scheme 20. In view of using the outer nitrogen atom of the imidazole ring for metal coordination, imidazolosubporphyrin was reacted with the (pentamethylcyclopentadienyl)iridium(III) dichloride dimer in the presence of a base. This reaction afforded a mixture of two isomeric complexes $\mathbf{4 7 a}$ and $\mathbf{4 7 b}$ where iridium(III) is bonded to the outer nitrogen atom and to the ortho-carbon atom of the adjacent meso phenyl group. Reaction of this mixture of isomers with diphenylacetylene in the presence of $\mathrm{KPF}_{6}$ afforded the phenyl-rearranged iridium(III) complexes $48 \mathrm{a}$ and $\mathbf{4 8 b}$ in $26 \%$ and $46 \%$ yields, respectively. The $\beta$-carbon atoms of imidazolosubporphyrin are bound to the iridium(III) atom and are assigned as carbenes: $\mathrm{C}(\beta)$-Ir bond lengths of $\sim 2.00 \AA$ and chemical shifts of these carbon atoms at 174.5 (complex 48a) and $170.4 \mathrm{ppm}$ (complex 48b) are in agreement with data reported for $\mathrm{NHC}-\mathrm{Ir}^{\prime \prime \prime}\left(\mathrm{Cp}^{\star}\right)$ complexes. These complexes are unprecedented examples of porphyrinoids possessing a carbene center at their framework. 




Scheme 20. Synthesis of NHC-Ir(III) complexes of imidazolosubporphyrins 48a and $\mathbf{4 8 b}$.

\subsection{Carbenaporphyrins}

A carbenaporphyrin ligand was obtained via a 1,3-dipolar cycloaddition reaction to form two triazole moieties (compound 49) which were alkylated to the respective triazolium macrocycle 50 (Scheme 21). ${ }^{[58]}$ Deprotonation of this precursor afforded the corresponding carbazole-triazolylidene porphyrin ligand. The authors notably reported the synthesis of lithium and scandium complexes 51-53. Interestingly, these complexes do not present aromatic or antiaromatic character of an 18 or $20 \pi$ electrons and the heterocyclic moieties keep their own aromaticity. However, corresponding metal complexes present geometric features of porphyrins with stronger electron donor properties due to the two opposite mesoionic NHC ligands. These ligands may found interesting applications in the near future.
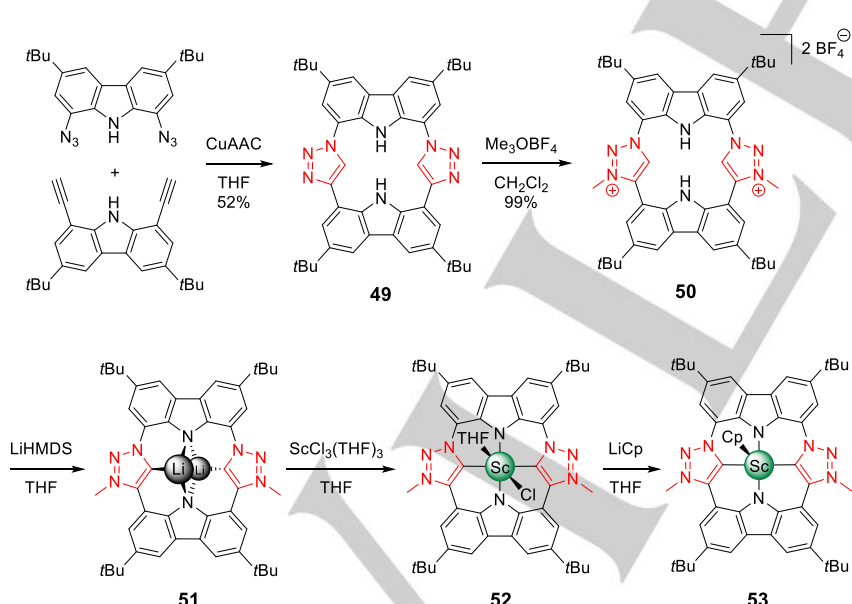

Scheme 21. Synthesis of carbenaporphyrin complexes 51-53.

\subsection{Norcorolles}

Norcorroles are ring-contracted porphyrinoids exhibiting distinct antiaromaticity because they have a $16 \pi$ electron conjugated system. Because of their antiraromatic character, these porphyrinoids are very reactive and offer new opportunities to obtain original $\pi$-conjugated systems. In the course of their studies, Shinokubo and co-workers showed that it is not possible to obtain NHC-metal complexes with norcorroles because carbenes are able to react with norcorrole cores. For example, they reported the insertion of silylene in a $\beta, \beta$-pyrrolic bond of the nickel(II) 5,15-meso-dimesitylnorcorrole 54 to obtain the silicon inserted porphyrinioid 55 exhibiting near infrared absorption (Scheme 21). ${ }^{[59]}$ This result encouraged Shinokubos's group to investigate the reactivity of norcorrole with carbenes, including NHCs. The reaction with in situ generated dichlorocarbene resulted in the double insertion of two chloromethine units to provide a mixture of 5,15-dichloroporphyrin $\mathbf{5 6}$ and chlorinated isopyricorroles $\mathbf{5 7}$ (Scheme 22). ${ }^{[60]}$ The ring expansion reaction to obtain the pyridine ring involves the preliminary formation of a cyclopropane ring through the addition of dichlorocarbene to a $\beta, \beta$-pyrrolic bond. NHCs exhibited a different reactivity towards norcorroles. The nucleophilic NHC attacked the 3-position of the norcorrole core and the subsequent proton transfer afforded the nonaromatic macrocycle $\mathbf{5 8}$ incorporating a diazafulvene segment in $46 \%$ yield (Scheme 22 ). Interestingly, the UV-visible absorption spectrum of this compound presents broad absorption bands in the near infrared region.

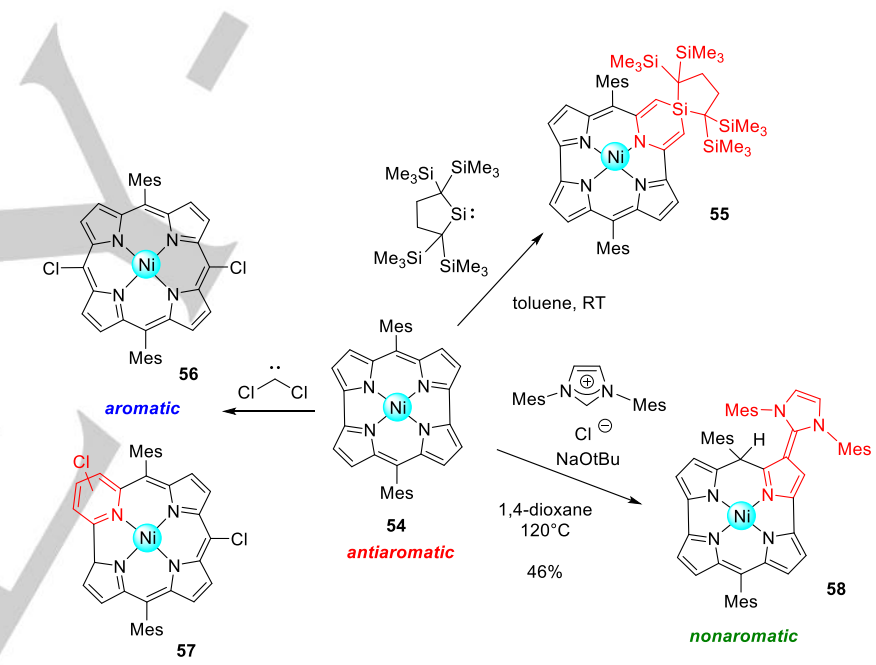

Scheme 22. Reactivity of norcorroles towards silylene, in situ generated dichlorocarbene and in situ generated NHC.

\section{Summary and Outlook}

Porphyrinoids and NHCs are relevant ligands in coordination and organometallic chemistry. As illustrated by the above discussion and other recent articles, ${ }^{[61]}$ several molecular systems combining porphyrins and $\mathrm{NHC}$ ligands were reported during the last decade. Axial coordination of NHCs on metalloporphyrins was mainly investigated for applications in catalysis, but some compounds such as iridium(III) complexes appeared as promising candidates for dual therapy against cancer. From a synthetic point of view, functionalizing porphyrin cores with NHC-metal complexes is a bit more challenging than axial ligation and requires more synthetic steps. These efforts led to the formation of some porphyrin derivatives containing peripheral NHC-based coordination sites in addition to their inner cavity. Linear and cofacial porphyrin dimers assembled from $\mathrm{NHC}$-metal bonds were reported according to the number of $\mathrm{NHC}$ 
ligands on meso positions. Porphyrins annulated to NHC ligands across two neighboring $\beta$-pyrrolic positions are the most investigated systems so far. It was notably shown that the intramolecular electronic interplay between metalloporphyrins and peripheral NHCs has dramatic consequences on the observed catalytic properties. These porphyrins fused to NHC ligands were also used for the synthesis of photosensitizers for PDT applications. Porphyrins fused to two opposed NHC ligands were used for the synthesis of main-chain organometallic polymers. Finally, molecular systems combining NHCs with other original porphyrinoids such as $\mathrm{N}$-confused porphyrins, subporphyrins and norcorroles were also reported with sometimes unexpected and beautiful structures. First seen as laboratory curiosities, molecular systems combining porphyrinoids and NHC ligands have found some interesting applications in catalysis and biomedicine. This research work also allowed to discover new ways to functionalize porphyrinoids. One of the major outlooks is probably the use of these molecular systems for dual catalysis combining transition-metal catalysis with photocatalysis or electrocatalysis.

Jean-François Longevial graduated from Montpellier University (France) under the supervision of Pr. A. Marra and Dr. S. Ulrich. He completed his PhD in 2017 on the synthesis of porphyrin derivatives fused to NHCs under the guidance of Dr. Sébastien Richeter. After a first postdoctoral position as a JSPS fellow with Pr. H. Shinokubo at Nagoya University (Japan), he is now working on heteroacenes chemistry with Dr. Olivier Siri at Marseille University (France).

Clémence Rose graduated from "Ecole Européenne de Chimie, Polymères et Matériaux" of Strasbourg. She completed her PhD in 2019 on the synthesis of cofacial porphyrin dimers assembled from NHCmetal bonds under the supervision of Dr. S Richeter. Nowadays, she is working as postdoctoral researcher on tetracycline derivatives with Pr. B. Figadère and Dr. L. Ferrié at the "Faculté de Pharmacie" of Paris-Saclay University (France).

Ludivine Poyac received her M.Sc degree in molecular materials for electronics and photonics from the Department of Chemistry at Angers University in 2020. She started her PhD on the synthesis of molecular systems combining porphyrins and $\mathrm{NHC}$ metal complexes for photocatalysis at Montpellier University under the supervision of Dr. Sébastien Richeter.

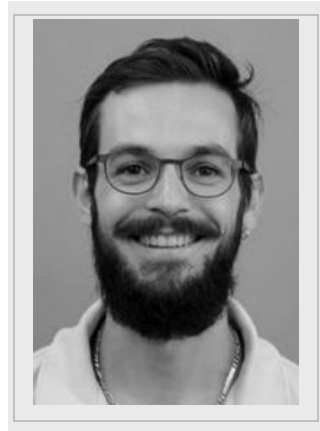

Sébastien Richeter completed his $\mathrm{PhD}$ in

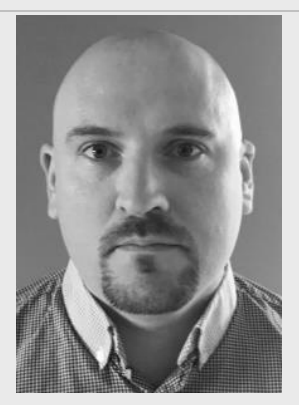
materials for applications ranging from biosensing and therapy to solar energy conversion. 2003 with Dr. H. J. Callot and Dr. R. Ruppert at the University of Strasbourg. After a postdoctoral position with Pr. J. Rebek Jr. at the Scripps Research Institute (La Jolla,

USA), he was appointed as Lecturer at the University of Montpellier (France) in 2004.

His current research topics include

porphyrins and other $\pi$-conjugated molecules for materials sciences and biomedical applications.

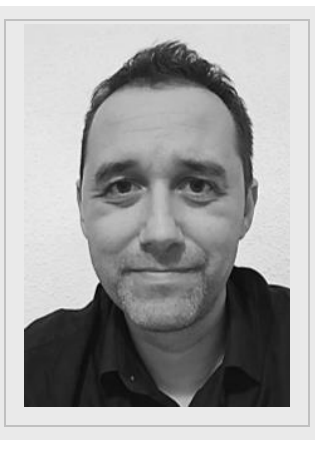

\section{Acknowledgements}

The authors are grateful to the University of Montpellier, the Centre National de la Recherche Scientifique (CNRS) and the French Ministry of Research for financial support. SR is grateful for financial support from the Agence Nationale de la Recherche (ANR-09-JCJC-0089-01: PORPH-NHC; ANR-19-CE07-0009-01: COmPaCt), the Région Languedoc-Roussillon (Research Grant "Chercheur(se)s d'Avenir - 2015-005984) and the FEDER program (Fonds Européen de Développement Régional).

Keywords: porphyrinoids $•$ carbene ligands $•$ catalysis $•$ antitumour agents $\cdot$ molecular electronics

[1] a) B. J. Anding, L. K. Woo in Handbook of Porphyrin Science, Vol. (Eds.: K. M. Kadish, R. Guilard, K. Smith), Elsevier Publishing, NJ, 1999 , Vol. 1, pp. 100-150; b) D. Dolphin, The Porphyrins V1: Structure and Synthesis, $1^{\text {st }}$ Edition, Structure and synthesis, Part A, Elsevier, 1978.

[2] M. O. Senge, Chem. Commun., 2011, 47, 1943-1960.

[3] a) E Tabor, J Połtowicz, K Pamin, S Basąg, W Kubiak, Polyhedron, 2016 119, 342-349; b) Ji-Y. Shin, H. Furuta, K. Yoza, S. Igarashi, A. Osuka, J. Am. Chem. Soc., 2001, 123, 29, 7190-7191; c) M Luciano, C Brückner, Molecules, 2017, 22, 980; d) D. Dolphin, The Porphyrins V3: Physical Chemistry, Part A, Elsevier, 1978.

[4] a) B. Röder, M. Büchner, I. Rückmanna, M. O. Senge, Photochem Photobiol. Sci., 2010, 9, 1152-1158; b) M. O. Senge, Chem. Commun. 2006, 243-256; c) M. O. Senge, S. A. MacGowan, J. M. O'Brien, Chem Commun., 2015, 51, 17031-17063.

[5] P. de Frémont, N. Marion, S. P. Nolan, Coord. Chem. Rev., 2009, 253 862-892. 
[6] a) H.-W. Wanzlick, F. Esser, H.-J. Kleiner, Chem. Ber. 1963, 96, 1208 1212; b) P. Bautista, M. Hunger, H. Noller, Angew. Chem., Int. Ed. 1968 7, 140-141.

[7] A. J. Arduengo, R. L. Harlow, M. Kline, J. Am. Chem. Soc., 1991, 113, 361-363.

[8] a) O. Schuster, L. Yang, H. G. Raubenheimer, M. Albrecht, Chem. Rev. 2009, 109, 8, 3445-3478; b) M. N. Hopkinson, C. Richter, M. Schedler F. Glorius, Nature, 2014, 510, 485-496; c) M. Albrecht, N-Heterocyclic Carbenes. Effective Tools for Organometallic Synthesis. Edited by S. P. Nolan, 2015, Wiley \& son, Wiley-CH.

[9] a) S. C. Sau, P. K. Hota, S. K. Mandal, M. Soleilhavoup, G. Bertrand, Chem. Soc. Rev., 2020, 49, 1233-1252. b) R. H. Crabtree, Coord. Chem. Rev. 2013, 257, 755-766.

[10] a) E. O. Fischer, R. Aumann, Chem. Ber.1969, 102, 1495-1503; b) K. H. Dötz, W. Kuhn, Angew. Chem. Int. Ed. 1983, 22, 732-732; c) K. H. Dötz, I. Pruskil J. Mühlemeier, Chem. Ber. 1982, 115, 1278- 1285; d) E. O Fischer, A. Maasböl, Angew. Chem., Int. Ed. 1964, 3, 580-581; e) D. Bourissou, O. Guerret, F. P. Gabbaï, G. Bertrand, Chem. Rev. 2000, 100 39-91

[11] H. Jacobsen, A. Correa, A. Poater, C. Costabile, L. Cavallo, Coord. Chem. Rev. 2009, 253, 687-703.

[12] R. A. Kelly, H. Clavier, S. Giudice, N. M. Scott, E. D. Stevens, J. Bordner, I. Samardjiev, C. D. Hoff, L. Cavallo, S. P. Nolan, Organometallics 2008 27, 202-210.

[13] F. Glorius, 2006, N-Heterocyclic Carbenes in Catalysis - An Introduction. In: N-Heterocyclic Carbenes in Transition Metal Catalysis. Topics in Organometallic Chemistry, vol 21. Springer, Berlin, Heidelberg.

[14] W Liu, R Gust, Chem. Soc. Rev., 2013, 42, 755-773.

[15] a) V Martínez-Agramunt, E Peris, Chem. Commun., 2019, 55, 14972 14975; b) C. Mejuto, G. Guisado-Barrios, D. Gusev, E. Peris, Chem Commun., 2015, 51, 13914-13917.

[16] S. Ibáñez, M. Poyatos, E. Peris, Acc. Chem. Res., 2020, 53, 7, 14011413.

[17] B. J. Anding, L. K. Woo in Handbook of Porphyrin Science, Vol. 21 (Eds.: K. M. Kadish, R. Guilard, K. Smith), World Scientific Publishing Company: Hackensack, NJ, 2012, Vol. 21, pp. 145-319.

[18] Y. Li, J.-S. Huang, Z.-Y. Zhou, C.-M. Che, J. Am. Chem. Soc. 2001, 123, 4843-4844.

[19] M. Albrecht, P. Maji, C. Häusl, A. Monney, H. Müller-Bunz, Inorg. Chim. Acta 2012, 380, 90-95.

[20] Z. Yao, H. Li, Y. Fan, X. Liang, X. Xu, J. Li, Dyes Pigm. 2020, 173, 107961

[21] J. Olguín, H. Müller-Bunz, M. Albrecht, Chem. Commun. 2014, 50, 3488 3490.

[22] B. J. Anding, A. Ellern, L. K. Woo, Organometallics 2014, 33, 2219-2229.

[23] T.-L. Lam, K.-C. Tong, C. Yang, W.-L. Kwong, X. Guan, M.-D. Li, V. KarYan Lo, S. Lai-Fung Chan, D. L. Phillips, C.-N. Lok, C.-M. Che, Chem. Sci. 2019, 10, 293-309.

[24] K-H. Chan, X. Guan, V. Kar-Yan Lo, C.-M. Che, Angew. Chem., Int. Ed. 2014, 53, 2982-2987.

[25] a) C. Samojłowicz, M. Bieniek, K. Grela, Chem. Rev. 2009, 109, 3708 3742; b) J. A. Cabeza, P. García-Álvarez, Chem. Soc. Rev. 2011, 40, 5389-5405.

[26] K.-P. Shing, Y. Liu, B. Cao, X.-Y. C., T. You, C.-M. Che, Angew. Chem., Int. Ed. 2018, 57, 11947-11951.

[27] Y. Li, J.-S. Huang, Z.-Y. Zhou, C.-M. Che, X.-Z. You, J. Am. Chem. Soc 2002, 124, 13185-13193.

[28] K. M. Smith, G. H. Barnett, B. Evans, Z. Martynenko, J. Am. Chem. Soc. 1979, 101, 5953-5961.

[29] a) M. C. Balaban, C. Chappaz-Gillot, G. Canard, O. Fuhr, C. Roussel, T. S. Balaban, Tetrahedron 2009, 65, 3733-3739; b) K. I. Yamashita, K. Kataoka, M. S. Asano, K.-I. Sugiura, Org. Lett. 2012, 14, 190-193.

[30] C. H. Devillers, S. Hebié, D. Lucas, H. Cattey, S. Clément, S. Richeter, J. Org. Chem. 2014, 79, 6424-6434

[31] J. Haumesser, J.-P. Gisselbrecht, J. Weiss, R. Ruppert, Chem. Commun 2012, 48, 11653-11655.

[32] J. Haumesser, J.-P. Gisselbrecht, L. Karmazin-Brelot, C. Bailly, J. Weiss, R. Ruppert, Organometallics 2014, 33, 4923-4930.

[33] S. Durot, J. Taesch, V. Heitz, Chem. Rev. 2014, 114, 8542-8578.
[34] a) J. P. Collman, P. Denisevich, Y. Konai, M. Marrocco, C. Koval, F. C. Anson, J. Am. Chem. Soc. 1980, 102, 6027-6036; b) S. Fukuzumi, K. Okamoto, C. P. Gros, R. Guilard, J. Am. Chem. Soc. 2004, 126, 10441 10449; c) K. M. Kadish, L. Fremond, J. Shen, P. Chen, K. Ohkubo, S. Fukuzumi, M. El Ojaimi, C. P. Gros, J.-M. Barbe, R. Guilard, Inorg. Chem. 2009, 48, 2571-2582; d) P. Peljo, L. Murtomäki, T. Kallio, H.-J. Xu, M. Meyer, C. P. Gros, J.-M. Barbe, H. H. Girault, K. Laasonen, K. Kontturi, J. Am. Chem. Soc. 2012, 134, 5974-5984; e) E. A. Mohamed, Z. N Zahran, Y. Naruta, Chem. Commun. 2015, 51, 16900-16903; f) E. A Mohamed, Z. N. Zahran, Y. Naruta, Chem. Mater. 2017, 29, 7140-7150.

[35] a) M.-M. Ga, J.-Q. Liu, L. Zhang, Y.-Y. Wang, F. E. Hahn, Y.-F. Han, Chem. Rev. 2018, 118, 9587-9641; b) N. Sinha, F. E. Hahn, Acc. Chem. Res. 2017, 50, 2167-2184; c) A. Rit, T. Pape, F. E. Hahn, J. Am. Chem. Soc. 2010, 132, 4572-4573; d) A. Rit, T. Pape, F. E. Hahn, Organometallics 2011, 30, 6393-6401; e) N. Sinha, F. Roelfes, A. Hepp, C. Mejuto, E. Peris, F. E. Hahn, Organometallics 2014, 33, 6898-6904; f) F. Al-Shnani, G. Guisado-Barrios, D. Sainz, E. Peris, Organometallics 2019, 38, 697-701.

[36] C. Rose, A. Lebrun, S. Clément, S. Richeter, Chem. Commun. 2018, 54, 9603-9606.

[37] S. Richeter, A. Hadj-Aïssa, C. Taffin, A. van der Lee, D. Leclercq, Chem Commun. 2007, 2148-2150.

[38] J.-F. Lefebvre, D. Leclercq, J.-P. Gisselbrecht, S. Richeter, Eur. J. Org. Chem. 2010, 1912-1920.

[39] M. Lo, J.-F. Lefebvre, N. Marcotte, C. Tonnelé, D. Beljonne, R. Lazzaroni, S. Clément, S. Richeter, Chem. Commun. 2012, 48, 3460-3462.

[40] J.-F. Longevial, A. Langlois, A. Buisson, C. H. Devillers, S. Clément, A van der Lee, P. D. Harvey, S. Richeter, Organometallics 2016, 35, 663 672.

[41] E. Peris, Chem. Rev. 2018, 118, 9988-10031.

[42] a) M. D. Sanderson, J. W. Kamplain, C. W. Bielawski, J. Am. Chem. Soc 2006, 128, 16514-16515; b) D. M. Khramov, E. L. Rosen, V. M. Lynch, C. W. Bielawski, Angew. Chem., Int. Ed. 2008, 47, 2267 - 2270; c) E. Rosen, C. D. Varnado, Jr., A. G. Tennyson, D. M. Khramov, J. W Kamplain, D. H. Sung, P. T. Cresswell, V. M. Lynch, C. W. Bielawski, Organometallics 2009, 28, 6695-6706; d) A. G. Tennyson, R. J. Ono, T. W. Hudnall, D. M. Khramov, J. A. V. Er, J. W. Kamplain, V. M. Lynch, J. L. Sessler, C. W. Bielawski, Chem. Eur. J. 2010, 16, 304-315; e) A. G. Tennyson, V. M. Lynch, C. W. Bielawski, J. Am. Chem. Soc. 2010, 132 9420-9429; f) A. T. Biju, K. Hirano, R. Fröhlich, F. Glorius, Chem. Asian J. 2009, 4, 1786-1789; g) B. M. Neilson, V. M. Lynch, C. W. Bielawski, Angew. Chem., Int. Ed. 2011, 50, 10322-10326; h) B. M. Neilson, C. W. Bielawski, J. Am. Chem. Soc. 2012, 134, 12693- 12699.

[43] a) B. Hildebrandt, W. Franck, C. Ganter, Organometallics 2011, 30 , 3483-3486; b) B. Hildebrandt, S. Raub, W. Frank, C. Ganter, Chem. Eur J. 2012, 18, 6670-6678.

[44] J.-F. Lefebvre, M. Lo, D. Leclercq, S. Richeter, Chem. Commun. 2011, 47, 2976-2978.

[45] a) T. Drçge, F. Glorius, Angew. Chem., Int. Ed. 2010, 49, 6940-6952; b) D. J. Nelson, S. P. Nolan, Chem. Soc. Rev. 2013, 42, 6723-6753.

[46] J.-F. Lefebvre, M. Lo, J.-P. Gisselbrecht, O. Coulembier, S. Clément, S Richeter, Chem. Eur. J. 2013, 19, 15652-15660.

[47] J.-F. Lefebvre, J.-F. Longevial, K. Molvinger, S. Clément, S. Richeter C.R. Chimie 2016, 19, 94-102.

[48] M. Abdelhameed, P.-L. Karsenti, A. Langlois, J.-F. Lefebvre, S. Richeter R. Ruppert, P. D. Harvey, Chem. Eur. J. 2014, 20, 12988-13001.

[49] a) D. Bellows, S. M. Aly, C. P. Gros, M. El Ojaimi, J.-M. Barbe, R. Guilard P. D. Harvey, Inorg. Chem. 2009, 48, 7613-7629; b) M. Abdelhameed, A Langlois, P.-L. Karsenti, S. Richeter, R. Ruppert, P. D. Harvey, Chem. Commun. 2014, 50, 14609-14612.

[50] J.-F. Longevial, K. El Cheick, D. Aggad, A. Lebrun, A. van der Lee, F. Tielens, S. Clément, A. Morère, M. Garcia, M. Gary-Bobo, S. Richeter, Chem. Eur. J. 2017, 23, 14017-14026.

[51] a) M. Lo, J.-F. Lefebvre, D. Leclercq, A. van der Lee, S. Richeter, Org. Lett. 2011, 13, 3110-3113; b) J. Rubio-Magnieto, F. Di Meo, M. Lo, C Delcourt, S. Clément, P. Norman, S. Richeter, M. Linares, M. Surin, Org Biomol. Chem. 2015, 13, 2453-2463.

[52] J.-F. Longevial, M. Lo, A. Lebrun, D. Laurencin, S. Clément, S. Richeter Dalton Trans. 2020, 49, 7005-7014. 
[53] a) K. A. Williams, A. J. Boydston, C. W. Bielawski, Chem. Soc. Rev. 2007, 36, 729-744; b) K. S. Song, D. Kim, K. Polychronopoulou, A. Coskun, ACS Appl. Mater. Interfaces 2016, 8, 26860-26867; c) C. Zhang, J.-J. Wang, Y. Liu, H. Ma, X.-L. Yang, H.-B. Xu, Chem. Eur. J. 2013, 19, 50045008; S. Gonell, M. Poyatos, E. Peris, Chem. Eur. J. 2014, 20, 5746 5751.

[54] M. Toganoh, T. Hihara, H. Furuta, Inorg. Chem. 2010, 49, 8182-8184.

[55] T. Yamamoto, M. Toganoh, S. Mori, H. Uno, H. Furuta, Chem. Sci. 2012 , 3, 3241-3248.

[56] D. Ren, S. Koniarz, X. Li , P. J. Chmielewski, Chem. Commun., 2020, 56, 4836-4839.

[57] K. Yoshida, A. Osuka, Angew. Chem., Int. Ed. 2018, 57, 338-342.

[58] T. Maulbetsch, D. Kunz, Angew. Chem., Int. Ed. 2020, ASAP article, DOI: 10.1002/anie.202013434

[59] T. Fukuoka, K. Uchida, Y. M. Sung, J.-Y. Shin, S.Ishida, J. M. Lim, S. Hiroto, K. Furukawa, D. Kim, T. Iwamoto, H. Shinokubo, Angew. Chem. Int. Ed. 2014, 53, 1506-1509.

[60] S.-Y. Liu, T. Fukuoka, N. Fukui, J.-Y. Shin, H. Shinokubo, Org. Lett. 2020 22, 4400-4403.

[61] a) A. T. P. C. Gomes, L. Da. S. M. Forezi, M., M. Q. Simões, D. T. Gonzaga, M. F. C. Cardoso, F. D. C. Da Silva, M. G. P. M. S. Neves, V. F. Ferreira, J. A. S. Cavaleiro, Synthesis 2018, 50, 2678-2692; b) J. Yang J. Liu, Y. Wang, J. Wang, J. Incl. Phenom. Macrocycl. Chem. 2018, 90, 15-37. 


\section{Entry for the Table of Contents}
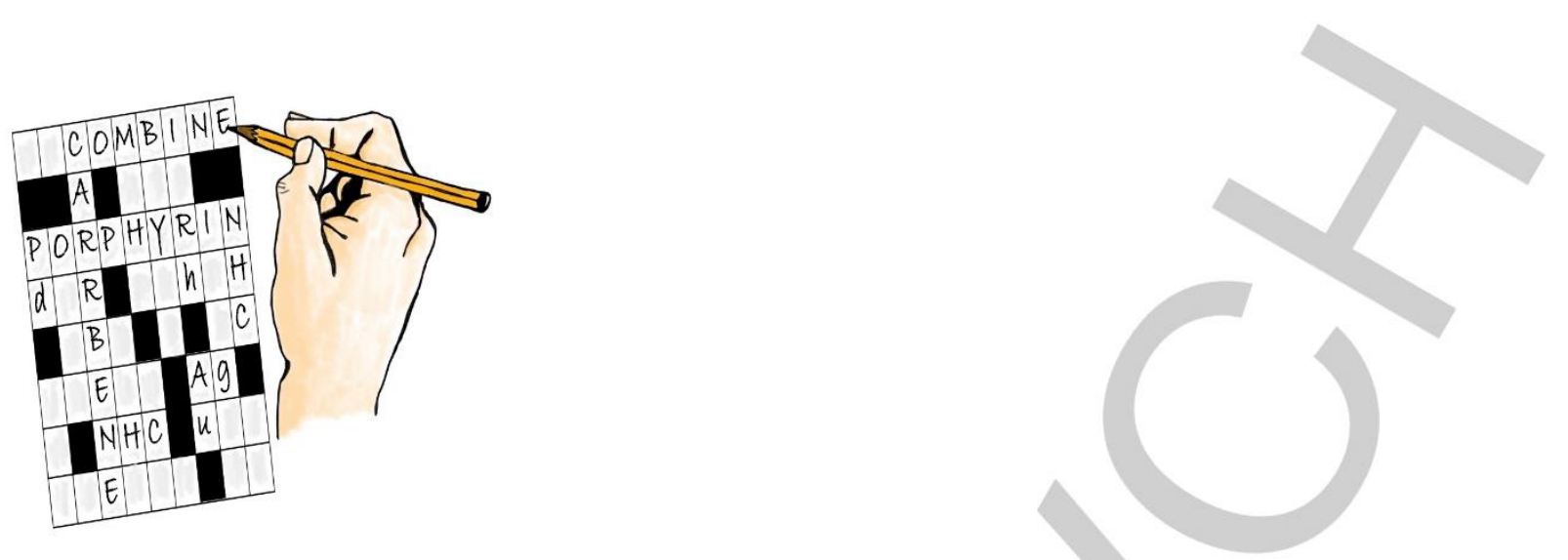

This review article compiles several examples of molecular species combining porphyrin derivatives and $\mathrm{N}$-heterocyclic carbene (NHC) ligands. Axial coordination of NHCs on metalloporphyrins and synthetic pathways to functionalize meso or $\beta$-pyrrolic positions of porphyrinoids with NHC-metal complexes are described. Structures and properties, including catalytic and biological properties, of these systems are presented along the discussion. 